\title{
El papel de los municipios en la prevención, ordenación y control de la contaminación lumínica
}

\author{
Lucía Casado Casado \\ Profesora Lectora de Derecho Administrativo \\ Universitat Rovira i Virgili
}

Sumario: I. INTRODUCCIÓN.-II. LA CONTAMINACIÓN LUMÍNICA: CUESTIONES GENERALES. 1. El concepto de contaminación lumínica. 2. Los principales efectos de la contaminación lumínica. 3 . El marco jurídico regulador de la contaminación lumínica. 3.1. La normativa estatal. 3.2. La normativa autonómica. 3.3. La normativa local. 4. Los principales instrumentos de prevención y control de la contaminación lumínica.III. LA CONTAMINACIÓN LUMÍNICA DESDE UNA PERSPECTIVA MUNICIPAL: UNA APROXIMACIÓN GENERAL. 1. Las competencias de los municipios en materia de contaminación lumínica. 2 . Los fines que deben orientar la actuación de los municipios sobre la contaminación lumínica. 3. Las posibles acciones de los municipios para la prevención, ordenación y control de la contaminación lumínica. 3.1. La aprobación de ordenanzas municipales. 3.2. La adopción de medidas sobre las instalaciones de alumbrado e iluminación exterior. 3.3. La zonificación y la planificación. 3.4. Otras medidas. 4. La necesaria colaboración de las administraciones supramunicipales.-IV. LAS COMPETENCIAS Y LAS OBLIGACIONES DE LOS MUNICIPIOS EN MATERIA DE CONTAMINACIÓN LUMÍNICA EN LA NORMATIVA AUTONÓMICA: ANÁLISIS DE LA LEGISLACIÓN CATALANA, BALEAR, NAVARRA Y CÁNTABRA. 1. La intervención de los municipios en la zonificación. 2. La intervención de los municipios a través del planeamiento urbanístico. 3. La intervención de los municipios sobre la iluminación exterior. 3.1. La fijación de valores de iluminación más estrictos que los establecidos con carácter general por la normativa autonómica. 3.2. La regulación del régimen horario del alumbrado. 3.3. El control de la iluminación en horario nocturno. 3.4. La obligación de adecuación de los alumbrados públicos municipales a las prescripciones normativas. 4. La incorporación del control lumínico en determinados mecanismos de intervención administrativa. 5. La intervención municipal de control, inspección y sanción.- V. BIBLIOGRAFÍA ESPECÍFICA SOBRE CONTAMINACIÓN LUMÍNICA.

\section{INTRODUCCIÓN}

En los últimos años, la protección del medio ambiente ha ido ganando un protagonismo creciente, no sólo entre las preocupaciones de la ciudadanía, sino también de las propias administraciones públicas, circunstancia fácilmente visible a través de su actividad normativa y de ejecución. Al mismo tiempo, ha ido produciéndose una progresiva apertura hacia nuevos ámbitos y sectores objeto de protección ambiental, extendiéndose la intervención administrativa hacia realidades impensables hace unos pocos años. Han aparecido, de este modo, junto a los tradicionales ámbitos de actuación (contaminación 
atmosférica, residuos, protección de las aguas...) nuevos ámbitos de intervención administrativa, como, entre otros, el de la contaminación acústica — sobre el que se ha producido un auténtico aluvión normativo en los últimos años y que ha dado lugar también a una abundante y novedosa jurisprudencia- ${ }^{1}$; el de la contaminación odorífera - aún carente de una regulación global en la legislación básica estatal o autonómica- ${ }^{2} ;$ o el de la contaminación electromagnética - a raíz de la problemática que ha aflorado con el rápido despliegue de las instalaciones de radiocomunicación, en especial de las antenas de base de telefonía móvil y de la alarma social generada por los posibles riesgos derivados de estas instalaciones para la salud humana- ${ }^{3}$. Tal es el caso también de la protección frente a la denominada contaminación lumínica, que en la medida en que puede ocasionar efectos negativos sobre el medio ambiente, además de implicar un uso irracional de un bien escaso como es la energía, está siendo objeto de atención por parte de algunas administraciones públicas, que, en el marco del artículo 45.2 de la Constitución Española ${ }^{4}$, han decidido mantener una posición activa al respecto.

De este modo, en nuestro país, está empezando a prestarse atención a este fenómeno desde algunas comunidades autónomas y algunos municipios y están viendo la luz las primeras regulaciones y las primeras medidas de interven-

\footnotetext{
${ }^{1}$ La bibliografía al respecto es abundante. Destacamos, especialmente, los siguientes estudios: ALONSo GARCía, M. C., «La responsabilidad patrimonial de los municipios ante su pasividad en el control del ruido», en Justicia Administrativa, núm. 23, 2004; Alonso GARCíA, M. C., El régimen jurídico de la contaminación atmosférica y acústica, Marcial Pons, Madrid, 1995; ARANA GARCía, E. y ToRres LÓPEZ, M. A. (coords.), Régimen jurídico del ruido. Una perspectiva integral y comparada, Comares, Granada, 2004; Cano Murcia, A., Régimen jurídico de la contaminación acústica. Comentarios a la Ley 37/2003, de 17 de noviembre, del Ruido, Aranzadi, Cizur Menor, 2004; De AndRÉs Alonso, F. L., El tratamiento administrativo de la contaminación acústica, Publicaciones del Valedor do Pobo, La Coruña, 2003; LóPEz RAMón, F., «La ordenación del ruido», en Revista de Administración Pública, núm. 157, 2002; Lozano Cutanda, B. (dir.), Comentario a la Ley del Ruido. Ley 37/2003, de 17 de noviembre, Thomson-Civitas, Madrid, 2004; MARÍn CASTÁN, F. (dir.), La tutela judicial frente al ruido, Cuadernos de Derecho Judicial, Consejo General del Poder Judicial, Madrid, 2002; Pérez Martos, J., Ordenación jurídica del ruido, Montecorvo, Madrid, 2003; PINEDo HAY, J., El ruido del ocio. Análisis jurídico de la contaminación acústica producida por las actividades de ocio, Bosch, Barcelona, 2001; y URiarte Ricote, M., «Contaminación acústica», en el libro dirigido por Iñaki LASAGABASTER Herrarte, Derecho Ambiental. Parte Especial, Instituto Vasco de Administración Pública, Oñati, 2004, pp. 613-734.
}

2 Sobre este tema, vid. CASAdo CASAdo, L., «La contaminación por olores: un reto normativo pendiente», en Revista Aranzadi de Derecho Ambiental, núm. 11, 2007, pp. 279-303.

${ }^{3}$ Sobre esta cuestión, vid., entre otros, los siguientes trabajos: DoméNECH PASCUAL, G., «El control municipal de la contaminación electromagnética», en la obra colectiva coordinada por José EsTEVE PARDo, Derecho del Medio Ambiente y Administración Local, $2^{\mathbf{a}}$ edición (1 ${ }^{\mathrm{a}}$ en la Fundación), Fundación Democracia y Gobierno Local, Barcelona, 2006, pp. 619-642; GonZÁLEZ GARCía, J. V., voz «Telecomunicaciones y medio ambiente», en la obra colectiva dirigida por Enrique Alonso García y Blanca Lozano CuTAnda, Diccionario de Derecho Ambiental, Iustel, Madrid, 2006, pp. 1203-1210; GonZÁlez GARCía, J. V., Infraestructuras de telecomunicaciones y Corporaciones locales, Aranzadi, Cizur Menor, 2003; Molina Jiménez, A., Las antenas de telefonía móvil. Régimen jurídico. Análisis de los impactos visuales y radioeléctricos en las comunicaciones móviles, Aranzadi, Pamplona, 2002; SANTAMARÍA ARINAS, R. J., «La normativa estatal sobre campos electromagnéticos generados por estaciones radioeléctricas», en Revista Aranzadi de Derecho Ambiental, núm. 2, 2003; y SANZ LARRUGA, F. J., La protección jurídica ante las radiaciones y la contaminación electromagnética, Aranzadi, Cizur Menor, 2004. 
EL PAPEL DE LOS MUNICIPIOS EN LA PREVENCIÓN, ORDENACIÓN Y CONTROL...

ción, aun sin existir todavía legislación básica estatal al respecto. En este contexto, los municipios, en ejercicio de sus competencias, principalmente sobre protección del medio ambiente y alumbrado público, están llamados a desarrollar un papel muy importante en la prevención, ordenación y control de esta modalidad de contaminación ${ }^{5}$. La normativa aprobada hasta el momento les atribuye amplias potestades y competencias, por lo que aparecen como administración con un papel activo en orden al cumplimiento de los objetivos establecidos en esta materia, y como garantes de su aplicación.

El objeto de este estudio es, precisamente, analizar las competencias y las vías de actuación de que disponen los municipios, en el ordenamiento jurídico vigente, para la prevención, ordenación y control de la contaminación lumínica, no sin antes realizar una aproximación general a este concepto, a los principales efectos que se derivan de esta nueva modalidad de contaminación y a su marco regulador.

\section{LA CONTAMINACIÓN LUMÍNICA: CUESTIONES GENERALES}

La iluminación artificial durante la noche resulta hoy imprescindible para la habitabilidad humana y es también necesaria para la realización de un gran número de actividades lúdicas, comerciales o productivas ${ }^{6}$. Sin embargo, la iluminación nocturna termina convirtiéndose, en muchos casos, en contaminación lumínica. Efectivamente, un diseño o un uso inadecuados de las instalaciones de alumbrado tiene consecuencias perjudiciales para la biodiversidad y el medio ambiente, en la medida en que se estén alterando, de manera desordenada, las condiciones naturales de oscuridad propias de las horas nocturnas. Además, «una iluminación nocturna excesiva o defectuosa constituye una forma de contaminación, en tanto que afecta a la visión del cielo, el cual forma parte del paisaje natural y ha de ser protegido, tanto porque se trata de un patrimonio común de todos los ciudadanos como por la necesidad de posibilitar su estudio científico» ${ }^{7}$. A continuación, se realiza una aproximación general a esta nueva forma de contaminación, sobre la que están comenzando a intervenir las administraciones públicas en aras de una mejor protección ambiental y un mayor ahorro energético. Para ello, se examina, en primer lugar, el concepto de contaminación lumínica, así como sus prin-

\footnotetext{
${ }^{4}$ El artículo 45.2 de la Constitución dispone que «Los poderes públicos velarán por la utilización racional de todos los recursos naturales, con el fin de proteger y mejorar la calidad de la vida y defender y restaurar el medio ambiente, apoyándose en la indispensable solidaridad colectiva».

5 Así lo destaca también JAUMe Fernández, C., «La contaminación lumínica en nuestros municipios. Reflexiones en torno a los instrumentos jurídicos para combatirla desde los Ayuntamientos», en Ayuntamiento XXI, núm. 4, 2002.

${ }^{6}$ Así lo pone de manifiesto el preámbulo de la Ley catalana 6/2001, de 31 de mayo, de ordenación ambiental del alumbrado para la protección del medio nocturno (primer párrafo).

${ }^{7}$ Preámbulo de la Ley catalana 6/2001, de 31 de mayo, párrafo segundo.
} 
cipales efectos, para analizar, posteriormente, el marco jurídico regulador y señalar los principales instrumentos de prevención y control en esta materia.

\section{El concepto de contaminación lumínica}

La contaminación lumínica se define, comúnmente, como «la emisión directa o indirecta hacia la atmósfera de luz procedente de fuentes artificiales por encima de la horizontal del foco de emisión. Esta luz enviada hacia el cielo que no es aprovechable, únicamente constituye un despilfarro de energía». Por su parte, CALvo CHARRO la define como «el resplandor producido por la luz artificial que se pierde y se escapa hacia el cielo procedente, principalmente, del alumbrado — público y privado-ineficiente, iluminando las partículas de agua y polvo que el aire contiene en suspensión, formando un inmenso globo de luz dirigido hacia el firmamento»". Este resplandor es debido a la mala calidad y orientación del alumbrado exterior.

Definiciones similares se encuentran en las normas autonómicas aprobadas hasta la fecha. Así, la Ley catalana 6/2001, de 31 de mayo, de ordenación ambiental del alumbrado para la protección del medio nocturno define la «contaminación lumínica» como «La emisión de flujo luminoso de fuentes artificiales nocturnas en intensidades, direcciones o rangos espectrales innecesarios para la realización de las actividades previstas en la zona en que se han instalado las luminarias» [art. 4.1.a) ${ }^{10}$. Y, en términos idénticos, la Ley 6/2006, de 9 de junio, de prevención de la contaminación lumínica de Cantabria [art. 2.a) $]^{11}$.

Se trata, por tanto, de un problema ambiental asociado a la iluminación artificial, bien pública (sistemas de alumbrado en calles, carreteras y otros

\footnotetext{
8 Sociedad de Ciencias Aranzadi (Departamento de Astronomía) y Cadem-Grupo Eve (Unidad DE TERCIARIO), Consideraciones sobre el uso racional de la energía y la contaminación lumínica en las instalaciones de alumbrado exterior, Diputación Foral de Guipúzcoa, 2006, p. 10.

9 Calvo Charro, M., «La contaminación lumínica. La protección del cielo oscuro», en su libro Escritos de Derecho Ambiental, Tirant lo Blanch, Valencia, 2003, p. 24.

${ }^{10}$ El Decreto 82/2005, de 3 de mayo, por el cual se aprueba el reglamento de desarrollo de la Ley 6/ 2001, de 31 de mayo, establece que «la contaminación luminosa se caracteriza por el aumento del fondo de brillo del cielo nocturno a causa de la dispersión de luz procedente de la iluminación artificial. Este aumento de luz artificial perturba y altera las propiedades del medio receptor y pone en riesgo la visión del cielo nocturno y el equilibrio y la función de los ecosistemas» (art. 4.2)

${ }^{11}$ De esta definición recogida en la legislación autonómica JAUME FERNÁNDEZ, C., «La contaminación lumínica...», cit. deriva cuatro elementos que permiten identificar y acotar el concepto legal: en primer lugar, sólo produce contaminación lumínica el flujo luminoso artificial, excluyéndose, por tanto, el flujo luminoso natural, como el procedente de los rayos solares o el producido por los rayos o relámpagos en una tormenta; en segundo lugar, debe proceder de fuentes artificiales nocturnas, lo que excluye los efectos contraproducentes que pueda provocar la luz artificial usada durante el día; en tercer lugar, cobra especial importancia la necesidad de zonificar el territorio en función de las distintas variables lumínicas; y, en cuarto lugar, debe existir una ausencia de proporción, equilibrio y razón entre la realización de las actividades previstas en la zona donde se encuentren instaladas las luces y la intensidad, dirección del foco de luz y rango espectral del mismo.
} 
EL PAPEL DE LOS MUNICIPIOS EN LA PREVENCIÓN, ORDENACIÓN Y CONTROL...

espacios o edificios públicos), bien privada (rótulos luminosos publicitarios, de establecimientos comerciales, haces de luz de los complejos de ocio orientados al cielo.... ${ }^{12}$. Nace, además, como consecuencia de un consumo indiscriminado e irracional de luz artificial y se traduce en un importante despilfarro energético. La emisión de luz a la atmósfera origina su dispersión en todas las direcciones por interacción con las moléculas del aire y su humedad. Además, la dispersión hacia el cielo aún se acentúa más si existen partículas contaminantes en la atmósfera y es claramente visible en forma de halo luminoso recubriendo las ciudades y amplias áreas en su entorno ${ }^{13}$, lo que supone la pérdida de la contemplación del cielo estrellado y una afección directa a lo que ha venido a denominarse el derecho a un cielo oscuro o estrellado ${ }^{14}$.

\section{Los principales efectos de la contaminación lumínica}

Los principales efectos ${ }^{15}$ que provoca la contaminación lumínica son tanto de carácter económico (abuso de los recursos naturales, gasto energético innecesario...), como ecológico (contaminación atmosférica, agresión al ecosistema nocturno que precisa la oscuridad para sobrevivir y mantener su equilibrio, afección a las aves migratorias, generación de residuos que contaminan gravemente el medio ambiente - residuos radiactivos, vertidos contaminantes en forma de gases, humos o aguas residuales-, abuso de los recursos naturales, sobreconsumo de combustibles fósiles, energía y recursos...) y social (intromisiones lumínicas que inciden en la vida privada de las personas afectadas, pérdida de las noches estrelladas y de contacto con la naturaleza, deslumbramiento que provoca inseguridad vial... $)^{16}$.

Sin embargo, a menudo, los efectos negativos de la contaminación lumínica, a pesar de ser fácilmente detectables por medio del sentido de la vista, pasan desapercibidos y se ignoran ${ }^{17}$. Estos efectos, tradicionalmente, no se han

\footnotetext{
${ }^{12}$ Fortes MARTín, A., «La creciente preocupación normativa por la protección ambiental del medio nocturno», en Ecosostenible, junio de 2005, p. 20.

13 Sociedad de Ciencias Aranzadi (Departamento de Astronomía) y Cadem-Grupo Eve (Unidad DE TERCIARIO), Consideraciones sobre el uso racional..., cit., p. 11.

${ }^{14}$ Calvo Charro, M., «La contaminación lumínica...», cit., pp. 27 y ss.

15 Como señala la Sociedad de Ciencias Aranzadi (Departamento de Astronomía) y Cadem-GruPO EVE (UNIDAD DE TERCIARIO), Consideraciones sobre el uso racional..., cit., "Aunque resulte un tanto extraño decirlo, hay que considerar esta novedosa forma de contaminación, cuyos efectos son todavía muy poco estudiados, como perfectamente equiparable a la emisión de humos hacia la atmósfera o al vertido de contaminantes en los ríos, porque, en el fondo, consiste en la emisión de energía producida artificialmente hacia un medio naturalmente oscuro» (p. 15).

16 Sobre los principales efectos causados por las instalaciones de alumbrado exterior, véase SoCIEDAD de Ciencias Aranzadi (Departamento de Astronomía) y Cadem-Grupo Eve (Unidad de TerciaRIO), Consideraciones sobre el uso racional..., cit., pp. 12-16.

17 Como pone de manifiesto la Sociedad de Ciencias Aranzadi (Departamento de Astronomía) y CADEM-GRUPo Eve (UNIDAD DE TERCIARIO), Consideraciones sobre el uso racional..., cit., "con el de-
} 
considerado por parte de las administraciones públicas, sino que han sido los colectivos de astrónomos y ecologistas, así como diversas organizaciones (por ejemplo, la Comisión Internacional de Iluminación, la Unión Astronómica Internacional o el Comité Español de Iluminación) los que han advertido de las consecuencias de la contaminación lumínica y han puesto de manifiesto esta problemática ${ }^{18}$. En España, algunas comunidades autónomas -y también algunos municipios - constituyen una meritoria excepción, habida cuenta que han regulado esta problemática. Cataluña ha sido la comunidad autónoma pionera en el tratamiento jurídico de la contaminación lumínica ${ }^{19}$.

Desde una óptica estrictamente jurídica, como ha puesto de relieve ENTRENA RUIZ, la contaminación lumínica "puede afectar a una serie de derechos de los ciudadanos que los poderes públicos están obligados a proteger y promover». Concretamente, este autor identifica los siguientes derechos entre los potencialmente afectados por la contaminación lumínica: el derecho al medio ambiente (art. 45 de la CE); el acceso a la cultura (art. 44.1 de la CE); la protección del patrimonio histórico-artístico (art. 46 de la $\mathrm{CE}$ ); la investigación científica y técnica (art. 44.2 de la CE); el derecho a la salud (art. 43.1 de la CE); e, incluso, el derecho a emplear el tiempo de ocio libremente, de acuerdo con nuestras aficiones particulares (art. 43.3 de la CE) ${ }^{20}$.

\section{El marco jurídico regulador de la contaminación lumínica}

La regulación de la contaminación lumínica en nuestro ordenamiento jurídico es reciente y nace en el ámbito municipal ${ }^{21}$, con la adopción de las primeras medidas de intervención y de las primeras ordenanzas ${ }^{22}$. A esta intervención local ha seguido, en algunas comunidades autónomas, la intervención autonómica, mediante la aprobación de leyes generales, restando aún pendiente la regulación global de este fenómeno a nivel estatal.

\footnotetext{
sarrollo industrial y el consiguiente aumento de población, nos enfrentamos a un tipo diferente y nuevo de contaminación; es la contaminación que no deja vestigios tan notorios (...), un tipo de contaminación cuya evidencia física no es tan palpable a primera vista» (p. 10).

18 Vid. RodríGUEz FonT, M., «La Llei catalana d'ordenació ambiental de l'enllumenat per a la protecció del medi nocturn», en Autonomies. Revista Catalana de Dret Públic, núm. 28, 2002, p. 84.

19 Vid. infra, el epígrafe siguiente de este mismo apartado.

${ }^{20}$ Entrena Ruiz, D., «La prevención contra la contaminación lumínica mediante la ordenación del territorio y urbanismo», en Ecosostenible, julio de 2005, p. 21.

${ }^{21}$ Como destaca Iparraguirre, J., «La contaminació lumínica i la resposta social», en SAM. Suport a la gestió ambiental d'activitats en el municipi, núm. 8, Diputación de Barcelona, junio de 2003, p. 42, ciudades como Figueres o Tárrega, pioneras en Cataluña en la adaptación del alumbrado, están consiguiendo ahorros medios de entre el $25 \%$ y el $30 \%$, unos retornos de inversión de entre dos y tres años y una muy buena aceptación de los cambios.

${ }^{22}$ Con anterioridad a la aprobación de la Ley 6/2001, algunos municipios catalanes ya habían aprobado ordenanzas sobre contaminación lumínica. Destacamos el Reglamento de protección del cielo nocturno de Tárrega (Boletín Oficial de la Provincia de Lleida, núm. 135, de 10 de noviembre de 1998); y el Reglamento de protección del cielo nocturno de Bellpuig (Boletín Oficial de la Provincia de Lleida, núm. 29, de 9 de marzo de 1999)
} 
EL PAPEL DE LOS MUNICIPIOS EN LA PREVENCIÓN, ORDENACIÓN Y CONTROL...

\subsection{La normativa estatal}

Actualmente, aún no existe una ley básica estatal reguladora de este tipo de contaminación, aunque empieza a notarse una preocupación generalizada por esta cuestión y a manifestarse la necesidad de contar con una regulación al respecto. Las iniciativas adoptadas por el legislador estatal hasta el momento han sido escasas ${ }^{23}$. Entre ellas, puede destacarse la aprobación de la Ley 31/1988, de 31 de octubre, de protección de la calidad astronómica de los Observatorios del Instituto de Astrofísica de Canarias, para la protección de la calidad astronómica en el ámbito territorial de las Islas de La Palma y de Tenerife; y del Real Decreto 243/1992, de 13 de marzo, que aprueba su reglamento de desarrollo. Asimismo, la normativa reguladora de la evaluación de impacto ambiental (el Real Decreto Legislativo 1302/1986, de 28 de junio, por el que se regula la evaluación de impacto ambiental; y el Real Decreto 1131/1988, de 30 de septiembre, que aprueba su reglamento de desarrollo) recogen algunas previsiones en relación con las emisiones luminosas, que deben ser tenidas en cuenta en este proceso ${ }^{24}$.

Este escaso tratamiento de la contaminación lumínica en la normativa estatal pone de manifiesto la necesidad de una Ley básica del cielo oscuro, sobre la cual ya viene llamando la atención, desde hace algún tiempo, la doctrina administrativista. Desde esta perspectiva, CALVO CHARRO ha destacado la conveniencia de contar con una norma estatal en esta materia que tenga en cuenta la calidad de vida urbana, la protección de la biodiversidad, el ahorro energético y la calidad del cielo nocturno para su elaboración; y que contemple amplias medidas de intervención (regulación de los niveles de iluminación, así como de los rendimientos de los tipos de luminaria a instalar; imposición de prohibiciones directas; exigencia de criterios de ahorro y eficiencia energética en el alumbrado público... $)^{25}$.

Esta necesidad de una norma estatal también ha sido advertida por el Senado, mediante la aprobación de una moción en la que se insta al Gobierno a la elaboración de un informe técnico sobre la contaminación lumínica en España, así como de una legislación básica sobre la materia que promueva la ecoeficiencia ${ }^{26}$; y en la Estrategia de Ahorro y Eficiencia Energética en España 2004-2012, aprobada el 28 de noviembre de 2003, en la que se pro-

\footnotetext{
${ }^{23}$ Sobre esta cuestión vid. Calvo Charro, M., «La contaminación lumínica...», cit., pp. 46-57.

24 Vid. Calvo Charro, M., «La contaminación lumínica...», cit., pp. 46-51.

25 Calvo Charro, M., «La contaminación lumínica...», cit., pp. 52-57.

${ }^{26}$ Debe destacarse que el Pleno del Senado, en la sesión celebrada el día 17 de mayo de 2005, aprobó la moción núm. 67, del Grupo Parlamentario Socialista, con la propuesta de modificación de los Grupos Parlamentarios Popular en el Senado, Socialista, de Senadores de Coalición Canaria, de Senadores Nacionalistas Vascos, Catalán en el Senado de Convergència i Unió y Entesa Catalana de Progreso, instando al Gobierno a la elaboración de un informe técnico sobre la contaminación lumínica en España, así como de una legislación básica sobre la materia que promueva especialmente la ecoeficiencia (Boletín Oficial de las Cortes Generales I, núm. 238, de 24 de mayo de 2005).
} 
pone, entre los instrumentos a aplicar en el subsector de alumbrado público -dentro del sector servicios públicos-, "el desarrollo de una normativa estatal, con la finalidad de disminuir también la contaminación lumínica, mediante la utilización de tecnologías eficientes energéticamente en el alumbrado exterior. Esta normativa tendería un desarrollo posterior a través de otras normativas de nivel autonómico y local, en función de las competencias respectivas $»^{27}$.

\subsection{La normativa autonómica}

La inexistencia de una ley básica estatal que, con carácter general, regule la contaminación lumínica y la protección del cielo oscuro, no ha constituido un obstáculo para que algunas comunidades autónomas, en ejercicio de sus competencias en materia de protección del medio ambiente, regulen esta cuestión. Entre ellas, ha sido pionera Cataluña, con la aprobación de la Ley 6/2001, de 31 de mayo, de ordenación ambiental del alumbrado para la protección del medio nocturno ${ }^{28}$, desarrollada posteriormente por el Decreto 82/ 2005 , de 3 de mayo $^{29}$. Aprobada por el Parlamento de Cataluña por unanimidad, representa un paso adelante muy importante en la prevención y en el control de la contaminación lumínica y, por tanto, en la protección y recuperación del cielo nocturno. Como ha puesto de relieve CALVO CHARRO, se trata de «una Ley absolutamente pionera en la defensa de la noche estrellada. Sin duda un ejemplo a seguir por otras Comunidades Autónomas e incluso por el legislador estatal. Constituye pues una Ley autonómica de protección del cielo oscuro en ausencia de legislación básica estatal en la materia» ${ }^{30}$.

\footnotetext{
27 Estrategia de Ahorro y Eficiencia Energética en España 2004-2012, Ministerio de Economía, 5 de noviembre de 2003, p. 21. En cuanto al contenido de esta norma estatal, se establece que «debería regular no sólo el nivel mínimo de eficiencia energética, sino que también tendrá que considerar los aspectos medioambientales relacionados con el consumo de energía en alumbrado público, como son la reducción de emisiones de CO2, y la reducción del resplandor luminoso nocturno originado por las instalaciones de alumbrado exterior. El fin es mantener al máximo posible las condiciones lumínicas naturales en las horas nocturnas, como medida para paliar los impactos negativos que la intensidad lumínica produce en los distintos ecosistemas, y prevenir y corregir sus efectos en la visión del cielo» (pp. 21-22). Puede consultarse en la siguiente página web: http://mityc.es/NR/rdonlyres/0527323BD56F-4218-BF30-15E21BF01A14/0/AprobacionEstrategia.pdf (último acceso el día 20 de marzo de 2007).

${ }^{28}$ Sobre el proceso de gestación de la Ley catalana 6/2001, de 31 de mayo, y las razones que condujeron a su aprobación, vid. RoDRÍGUEZ FonT, M., «La Llei catalana...», cit., pp. 86-88.

${ }^{29}$ Contra este Decreto se presentaron dos recursos contencioso-administrativos. Uno fue interpuesto por Cel Fosc, Asociación contra la Contaminación Lumínica (el núm. 228/2005) y admitido a trámite por la Sección Tercera de la Sala Contencioso-Administrativa del Tribunal Superior de Justicia de Cataluña (vid. DOGC núm. 4481, de 3 de octubre de 2005); y el otro (el núm. 229/2005), por la Cámara Oficial de Comercio, Industria y Navegación de Barcelona y admitido a trámite por la Sección Tercera de la Sala Contencioso-Administrativa del Tribunal Superior de Justicia de Cataluña (vid. DOGC núm. 4485, de 7 de octubre de 2005), si bien posteriormente fue retirado.

${ }^{30}$ Calvo Charro, M., «El derecho a ver las estrellas. Análisis de la contaminación lumínica desde una perspectiva jurídica», en Revista de Derecho Urbanístico y Medio Ambiente, núm. 187, 2001, pp. 166-167.
} 
EL PAPEL DE LOS MUNICIPIOS EN LA PREVENCIÓN, ORDENACIÓN Y CONTROL...

A esta Ley han seguido la Ley 3/2005, de 20 de abril, de protección del medio nocturno de las Islas Baleares; la Ley Foral de Navarra 10/2005, de 9 de noviembre, de ordenación del alumbrado para la protección del medio nocturno; y la Ley 6/2006, de 9 de junio, de prevención de la contaminación lumínica de Cantabria, todas ellas aún pendientes de desarrollo reglamentario. En estas tres leyes autonómicas se advierte una gran influencia de la Ley catalana. En particular, las dos primeras son prácticamente idénticas a la catalana.

Estas leyes autonómicas tienen por objeto la regulación de las instalaciones y los aparatos de alumbrado exterior e interior, por lo que respecta a la contaminación lumínica que pueden producir ${ }^{31}$. Se trata de establecer las condiciones que deben cumplir las nuevas instalaciones de alumbrado exterior, tanto públicas como privadas, situadas en estas comunidades autónomas, así como las medidas correctoras a aplicar en las instalaciones existentes inadecuadas, con la finalidad de mejorar la protección del medio ambiente mediante un uso eficiente y racional de la energía que consumen y la reducción del resplandor luminoso nocturno. Todo ello sin menoscabo de la seguridad que debe proporcionar el alumbrado a los peatones, vehículos y propiedades ${ }^{32}$.

Con ello se pretende conseguir la eficiencia y ahorro energético de los sistemas de iluminación, sin mengua de la seguridad; la protección frente a las intrusiones y molestias lumínicas; la preservación del medio natural durante las horas nocturnas; y la defensa del paisaje, la prevención y corrección de los efectos de la contaminación lumínica en la visión del cielo y la garantía, en lo posible, de la visión nocturna del cielo ${ }^{33}$.

Para dar cumplimiento a estas finalidades, estas normas autonómicas regulan determinados mecanismos — de los cuales daremos cuenta más adelante $^{34}$ - que permiten dar respuesta a la problemática que plantea un alumbrado nocturno inadecuado, y a las formas de contaminación lumínica que se deriven, sin olvidar la importancia que el alumbrado nocturno tiene como elemento esencial para la seguridad ciudadana, para la circulación y también para la vida comercial, turística y recreativa de las zonas habitadas. Asimismo, fijan el ámbito de actuación que corresponde a las administraciones autonómicas y a las administraciones locales ${ }^{35}$.

\footnotetext{
${ }^{31}$ Vid. el artículo 1 de la Ley catalana 6/2001, de la Ley balear 3/2005, de la Ley Foral 10/2005 y de la Ley cántabra 6/2006.

${ }^{32}$ Así lo pone de manifiesto el artículo 1 de la Ley balear 3/2005, de la Ley Foral 10/2005 y de la Ley cántabra 6/2006.

33 Vid. los artículos 2 de la Ley catalana 6/2001, de la Ley balear 3/2005 y de la Ley Foral 10/2005; y 3 de la Ley cántabra 6/2006. Como novedad, la Ley Foral de Navarra 10/2005, de 9 de noviembre, de ordenación del alumbrado para la protección del medio nocturno, añade una quinta finalidad, no prevista en la legislación catalana: «Contribuir a cumplimentar la Directiva Europea sobre gestión de residuos y restricción del uso de sustancias peligrosas en equipos eléctricos y electrónicos [art. 2.e)].

34 Vid. el apartado II.4 de este estudio.

${ }_{35}$ Sobre las competencias locales, vid. infra, el apartado IV de este trabajo.
} 
En cuanto al ámbito de aplicación de estas medidas, debe tenerse en cuenta que las prescripciones de estas normas autonómicas se extienden generalmente a las instalaciones, aparatos o fuentes de iluminación exterior, tanto públi$\cos ^{36}$ como privados, así como a los alumbrados interiores, de carácter público o privado, si producen intrusión lumínica hacia el exterior ${ }^{37}$. También se recogen algunas exclusiones, de manera que se excluyen de su ámbito de aplicación, por ejemplo, los puertos, los aeropuertos, las instalaciones ferroviarias, las carreteras, las autovías y las autopistas; las instalaciones de las Fuerzas y los Cuerpos de Seguridad y las instalaciones de carácter militar; los sistemas de alumbrado o señalización de los vehículos a motor; las infraestructuras cuya iluminación esté regulada por normas destinadas a garantizar la seguridad de la ciudadanía $a^{38}$; o las instalaciones legalmente autorizadas generadoras de emisiones lumínicas como consecuencia de la combustión de productos y que no tengan la iluminación como finalidad principal ${ }^{39}$.

\subsection{La normativa local}

Junto con la normativa autonómica, merece ser destacada la importancia de las ordenanzas locales en la defensa del cielo oscuro. Además, no puede olvidarse que, en España, el problema de la contaminación lumínica se aborda inicialmente desde el ámbito local. Las competencias que la Ley 7/1985, de 2 de abril, reguladora de las bases del régimen local (en adelante, LBRL), atribuye a los municipios en materia de medio ambiente y alumbrado público ${ }^{40}$, unida a la potestad normativa de que gozan ${ }^{41}$, justifican la aprobación de

\footnotetext{
${ }^{36}$ Estas leyes afectan, por tanto, directamente a las administraciones públicas en tanto que titulares de instalaciones o fuentes de iluminación exterior (piénsese, por ejemplo, en la iluminación de edificios o espacios públicos), especialmente a la administración local, propietaria de la mayoría de las instalaciones de alumbrado público.

37 Véase, por ejemplo, el artículo 4.2 de la Ley cántabra 6/2006, el cual dispone que «La Ley afecta y se refiere de modo general a las instalaciones y luminarias exteriores. No obstante, se sujetarán también a sus prescripciones los alumbrados interiores, sean de carácter público o privado, cuando el flujo luminoso exceda de manera notoria y ostensible el ámbito espacial necesario para garantizar la utilidad de la instalación de que se trate».

38 En el caso de Cataluna, el Decreto 82/2005, de 3 de mayo, ha matizado estas exclusiones y ha concretado que las instalaciones de iluminación exterior de las infraestructuras descritas en el artículo 3.1 de la Ley 6/2001 están exentas del cumplimiento de las obligaciones fijadas en este Reglamento, exclusivamente en aquellos espacios, elementos funcionales y áreas de protección o zonas de servicio de las instalaciones destinadas a las finalidades propias de la infraestructura (art. 3.2).

39 Véanse los artículos 3 de la Ley de Cataluña 6/2001; 3 de la Ley de las Islas Baleares 3/2005; 5 de la Ley Foral 10/2005; y 4 de la Ley de Cantabria 6/2006. Las comunidades autónomas de Islas Baleares y Navarra han previsto que en estos casos de exención, el Gobierno autonómico (o, en el caso de Islas Baleares, también los consejos insulares), promoverá mediante convenios de colaboración con los organismos responsables la consecución del mayor número posible de las finalidades establecidas por sus respectivas leyes reguladoras de la contaminación lumínica que sean compatibles con la actividad de los referidos ámbitos de exención (vid. arts. 3.2 de la Ley balear 3/2005; y 5.2 de Ley Foral 10/2005).

40 Sobre las competencias municipales en materia de contaminación lumínica, vid. infra el apartado III.1 de este trabajo.

${ }^{41}$ Artículo 4.1.a) de la LBRL.
} 
EL PAPEL DE LOS MUNICIPIOS EN LA PREVENCIÓN, ORDENACIÓN Y CONTROL...

ordenanzas municipales para la defensa del cielo oscuro ${ }^{42}$, ordenanzas que han sido aprobadas ya por muchos ayuntamientos en España ${ }^{43}$. Baste, por el momento, con este apunte, ya que más adelante analizaremos con más detalle la potestad normativa local en este ámbito ${ }^{44}$.

\section{Los principales instrumentos de prevención y control de la contaminación lumínica}

La normativa vigente incorpora numerosos mecanismos de prevención y control de la contaminación lumínica ${ }^{45}$. En primer lugar, uno de los principales instrumentos que recoge la normativa autonómica y local para dar respuesta a la problemática que plantea la contaminación lumínica es la zonificación, mediante la división del territorio en diversas zonas en función de las características y peculiaridades de cada una en relación con el brillo que puede ser admisible. Estas zonas son E1 (áreas incluidas en la red de espacios naturales protegidos o en ámbitos territoriales que deban ser objeto de una protección especial, por razón de sus características naturales o de su valor astronómico, en las cuales sólo se puede admitir un brillo mínimo), E2 (áreas incluidas en ámbitos territoriales que sólo admiten un brillo reducido), E3 (áreas incluidas en ámbitos territoriales que admiten un brillo medio), E4 (áreas incluidas en ámbitos territoriales que admiten un brillo alto) y puntos de referencia (puntos próximos a las áreas de valor astronómico o natural especial, incluidas en la zona E1, para los que hay que establecer una regulación específica en función de la distancia que guarden con las zonas de mayor vulnerabilidad $)^{46}$.

\footnotetext{
42 Calvo Charro, M., «La contaminación lumínica...», cit., p. 65.

43 Véanse, a título de ejemplo, las Ordenanzas reguladoras de la ordenación ambiental de la iluminación exterior para la protección del medio nocturno, de ahorro de energía y contaminación lumínica del Ayuntamiento de Sant Boi de Llobregat; de protección del cielo nocturno del Ayuntamiento de Viladecans; o la Ordenanza sobre protección del cielo nocturno de Córdoba, aprobada en 1999, que, sin embargo, ha sido objeto de importantes críticas. En este sentido, GALADÍ-ENRíQUEZ, D., «La ordenanza sobre protección del cielo nocturno en Córdoba: un caso de interés general que debe hacernos reflexionar», en Tribuna de Astronomía y Universo, núm. 5, noviembre de 1999.
}

44 Vid. infra el apartado III.3.1 de este artículo.

45 Sobre esta cuestión, centrado en el ámbito de Cataluña, vid. CASADo CASADO, L., «Las administraciones públicas ante la contaminación lumínica. Análisis del modelo de prevención y control instaurado en Cataluña», en Revista Española de Derecho Administrativo, núm. 134, 2007, pp. 321-358.

46 Artículos 5 de la Ley de Cataluña 6/2001, 5 de la Ley de Baleares 3/2005, 6 de la Ley de Navarra 10/2005 y 7 de la Ley de Cantabria 6/2006. En cuanto a los criterios para el establecimiento de las diferentes zonas del territorio, todas las leyes autonómicas remiten a su desarrollo reglamentario. El Decreto catalán 82/2005, único aprobado hasta ahora, opta por utilizar como criterio para la zonificación el de la clasificación y calificación urbanística del suelo. De este modo, la zonificación toma como punto básico de referencia el planeamiento urbanístico, lo cual ha sido objeto de numerosas críticas porque prácticamente se deja en manos del planificador urbanístico, que es quien determinará la clasificación y la calificación del suelo dentro de su término municipal, la determinación de cada tipo de zona. Sobre este tema, vid. CASADo CASADO, L., «Las administraciones públicas...», cit., pp. 330-334 y ENTRENA RUIZ, D., «La prevención contra la contaminación lumínica mediante la ordenación del territorio y urbanismo», en Ecosostenible, julio de 2005, pp. 24-25. 
En segundo lugar, otra medida es el establecimiento de determinadas prohibiciones generales (como, por ejemplo, las fuentes de luz que, mediante proyectores convencionales o láseres, emitan por encima del plano horizontal; los artefactos y dispositivos aéreos de publicidad nocturna; la iluminación permanente de las pistas de esquí... ${ }^{47}$ y la obligación de respetar determinadas limitaciones, como los valores lumínicos que puedan establecerse para los diferentes usos.

En tercer lugar, de gran interés en esta materia resulta la fijación de las características de las instalaciones y los aparatos de iluminación. Para prevenir la contaminación lumínica y favorecer el ahorro, el uso adecuado y el aprovechamiento de la energía, es fundamental fijar las prescripciones técnicas que deben satisfacer las instalaciones y aparatos de iluminación; regular los tipos de lámparas que deben utilizarse, la inclinación y dirección de los aparatos de iluminación, los flujos de hemisferio superior instalado, el deslumbramiento y la intrusión lumínica; las condiciones mínimas de mantenimiento y conservación de las instalaciones y aparatos de iluminación; implementar sistemas de regulación de flujo de la luz... Asimismo, también es posible la adopción de medidas en torno a las características fotométricas de los pavimentos, con el fin de que resulten adecuadas para las instalaciones de alumbrado público ${ }^{48}$.

En cuarto lugar, otra medida de intervención comúnmente utilizada es el establecimiento de un régimen horario del alumbrado ${ }^{49}$, imponiéndose con carácter general la obligación de mantener apagado en horario nocturno el alumbrado exterior, excepto por razones de seguridad; para iluminar calles, caminos, viales, lugares de paso y, mientras sean destinadas a este uso, zonas de equipamiento y de aparcamiento; para usos comerciales, industriales, agrícolas, deportivos o recreativos, durante el tiempo de actividad; y por otros motivos justificados.

En quinto lugar, la incorporación del control lumínico como elemento determinante a tener en cuenta para la concesión de licencias (licencias de obras, licencias ambientales, licencias de apertura de establecimientos...) o en los procedimientos de evaluación de impacto ambiental tiende, asimismo, a conseguir la prevención de la contaminación lumínica ${ }^{50}$. En esta misma lí-

\footnotetext{
47 Véanse los artículos 6.6 de la Ley catalana 6/2001, 6.5 de la Ley balear 3/2005, 7.5 de la Ley navarra 10/2005 y 11 de la Ley cántabra 6/2006.

48 Véanse los artículos 8 de la Ley de Baleares 3/2005, 9 de la Ley de Navarra 10/2005 y 9 de la Ley de Cantabria 6/2006 (este precepto también prevé que estos aspectos serán tenidos en cuenta por las administraciones públicas en el ámbito de esta comunidad autónoma para su inclusión en los pliegos de prescripciones técnicas particulares de los contratos de obra).

${ }^{49}$ Véanse los artículos 8 de la Ley catalana 6/2001, 9 de la Ley balear 3/2005, 10 de la Ley navarra 10/2005 y 10 de la Ley cántabra 6/2006.

50 Véanse los artículos 10 de la Ley de Cataluña 6/2001, 11 de la Ley de Baleares 3/2005, 12 de la Ley de Navarra 10/2005 y 13 de la Ley de Cantabria 6/2006.
} 
EL PAPEL DE LOS MUNICIPIOS EN LA PREVENCIÓN, ORDENACIÓN Y CONTROL...

nea se sitúa la inclusión de los criterios de prevención y corrección de la contaminación lumínica en los pliegos de condiciones de los contratos administrativos en los que proceda $a^{51}$; y la verificación de su cumplimiento en las construcciones, instalaciones y viviendas sufragadas con fondos públicos ${ }^{52}$.

En sexto lugar, son muy importantes en esta materia los instrumentos económicos, dado el coste de implementación de muchas de las medidas de prevención y control de la contaminación lumínica. Desde esta perspectiva, algunas leyes autonómicas han creado un fondo económico para la prevención de la contaminación lumínica y la mejora de la eficiencia energética, afectado a la implantación de las medidas en ellas previstas ${ }^{53}$, y han previsto un régimen de ayudas específicas ${ }^{54}$.

Finalmente, cabe hacer referencia a las medidas de control e inspección y a las medidas sancionadoras, a fin de garantizar el cumplimiento de las prescripciones normativas y dotar de efectividad las medidas establecidas ${ }^{55}$

\section{LA CONTAMINACIÓN LUMÍNICA DESDE UNA PERSPECTIVA MUNICIPAL: UNA APROXIMACIÓN GENERAL}

Realizada esta aproximación general a la contaminación lumínica, se analizan ahora las competencias de los municipios, así como las posibles vías de actuación municipal que pueden llevarse a cabo para la prevención, ordenación y control de la contaminación lumínica.

\section{Las competencias de los municipios en materia de contaminación lumínica}

La Constitución Española reconoce y garantiza la autonomía de los municipios y provincias para la gestión de sus propios intereses (arts. 137 y 140), aunque no enumera ni concreta las competencias específicas de que dispo-

\footnotetext{
${ }^{51}$ Véanse los artículos 11.1 de la Ley catalana 6/2001, 12.1 de la Ley balear 3/2005, 13.1 de la Ley navarra 10/2005 y 13.4 de la Ley cántabra 6/2006.

${ }^{52}$ Véanse los artículos 12 de la Ley catalana 6/2001, 13 de la Ley balear 3/2005 y 14 de la Ley navarra $10 / 2005$.

${ }^{53}$ Véanse los artículos 13 de la Ley catalana 6/2001, 15 de la Ley balear 3/2005 y 14 de la Ley cántabra 6/2006

${ }^{54}$ Véanse los artículos 14 de la Ley catalana 6/2001, 16 de la Ley balear 3/2005, 15 de la Ley navarra 10/2005 y 15 de la Ley cántabra 6/2006.

55 Vid. los artículos 15 y ss. de la Ley catalana 6/2001, 17 y ss. de la Ley balear 3/2005, 16 y ss. de la Ley navarra 10/2005 y 16 y ss. de la Ley cántabra 6/2006.
} 
nen estas administraciones públicas. Sin embargo, la efectividad de la autonomía local hace del todo necesario que los entes locales dispongan de competencias sobre aquellas materias que sean de su interés. Y, sin duda, la protección del medio ambiente frente a la contaminación lumínica debe integrarse entre los intereses a gestionar por las administraciones locales, como veremos a continuación.

Ante el silencio del Texto constitucional, corresponde al legislador - estatal y autonómico - establecer el haz competencial que corresponde a la autonomía local garantizada por la Norma Suprema. La definición de las competencias locales en materia de medio ambiente se ha producido por una doble vía: por la legislación reguladora del régimen local, que establece unas previsiones genéricas en la materia y recoge una serie de servicios mínimos de prestación obligatoria; y por la legislación sectorial ambiental —estatal y autonómica, de acuerdo con el sistema de distribución competencial que rige en este ámbito-, que debe definir en cada sector y en cada materia ambientales el círculo de intereses que corresponde gestionar a los entes locales, dentro del respeto a la autonomía local.

En el ámbito concreto que centra nuestra atención, las competencias municipales en materia de contaminación lumínica se recogen tanto en la legislación de régimen local como en las escasas normas autonómicas aprobadas hasta la fecha. En cuanto a la normativa local, la LBRL atribuye a los municipios competencias relacionadas tanto con la protección del medio ambiente como con el alumbrado público. El punto de partida es el artículo 2 de la LBRL. Para garantizar la efectividad de la autonomía local, este precepto prevé que

«la legislación del Estado y la de las Comunidades Autónomas, reguladora de los distintos sectores de acción pública, según la distribución constitucional de competencias, deberá asegurar a los Municipios, las Provincias y las islas su derecho a intervenir en cuantos asuntos afecten directamente al círculo de sus intereses, atribuyéndoles las competencias que proceda en atención a las características de la actividad pública de que se trate y a la capacidad de gestión de la Entidad Local, de conformidad con los principios de descentralización y de máxima proximidad de la gestión administrativa a los ciudadanos».

En la medida en que la protección del medio ambiente y el alumbrado público constituyen materias que afectan directamente a los intereses locales y a las necesidades de la comunidad vecinal, la propia LBRL las configura, más adelante, como competencia propia municipal. Además, la legislación sectorial deberá efectuar las correspondientes previsiones competenciales, de acuerdo con los principios o directrices establecidos en el artículo 2 de la LBRL. Estas previsiones se complementan en los artículos 25 y 26 de la LBRL. Concretamente, el artículo 25, después de prever que el municipio, "para la gestión de sus intereses y en el ámbito de sus competencias, puede promover toda clase de actividades y prestar cuantos servicios públicos con- 
EL PAPEL DE LOS MUNICIPIOS EN LA PREVENCIÓN, ORDENACIÓN Y CONTROL...

tribuyan a satisfacer las necesidades y aspiraciones de la comunidad vecinal» (apartado 1), recoge como competencia propia municipal — que se ejercerá en los términos de la legislación del Estado y de las Comunidades Autónomas- la protección del medio ambiente [art. 25.2.f)] y el alumbrado público [art. 25.2.1)], así como la ordenación, gestión, ejecución y disciplina urbanística [art. 25.2.d)] $]^{56}$. Asimismo, el artículo 26 recoge como servicio municipal obligatorio que deberán prestar todos los municipios el alumbrado público [art. 26.1.a)] y como servicio obligatorio para los de población superior a 50.000 habitantes, el de protección del medio ambiente [art. 26.1.d)].

Respecto a la legislación sectorial, las normas autonómicas aprobadas hasta el momento en Cataluña, Islas Baleares, Comunidad Foral de Navarra y Cantabria también confieren amplias competencias a los entes locales, erigiéndolos en administraciones protagonistas en la aplicación y gestión de este nuevo ámbito de actuación ambiental ${ }^{57}$.

A la vista de lo expuesto, queda plenamente justificada la competencia de los municipios para intervenir en el ámbito de la contaminación lumínica, aun en aquellas Comunidades Autónomas que no cuentan con legislación específica en este ámbito. En efecto, la competencia sobre el alumbrado público y la configuración de esta materia como servicio público obligatorio, unida a las competencias en materia ambiental, justifican y amparan la actuación municipal en este ámbito. Corresponde a los municipios, por tanto, la regulación del servicio público de alumbrado público, que comprende «la determinación del diseño de las instalaciones de alumbrado y de la infraestructura aneja a ellas, su alcance y régimen de funcionamiento, que implica la correcta ordenación de la energía que le sirve de soporte, conforme a los principios de continuidad y regularidad en la prestación ${ }^{58}$. Además, en la actualidad, en el marco del artículo 45.2 de la Constitución y de las exigencias que de él se derivan (velar por la utilización racional de todos los recursos naturales), la regulación de este servicio debe incluir el establecimiento de previsiones ambientales y tomar en consideración, con la finalidad de evitar la contaminación lumínica procedente de las instalaciones exteriores, aspectos como la calidad de la iluminación, la orientación, la reducción del consumo energético.... ${ }^{59}$.

Estas competencias de que disponen todos los municipios en el marco de la LBRL han sido objeto de mayores concreciones y especificaciones en las

\footnotetext{
${ }^{56}$ Esta competencia tiene gran importancia en la temática que nos ocupa, toda vez que «las instalaciones de alumbrado público se han de incluir en las obras de urbanización previstas para la ejecución del planeamiento urbanístico (...) y que las instalaciones de alumbrado de titularidad privada constituyen usos del suelo sometidos a licencia municipal» (Propuesta de Modelo de Ordenanza Municipal de Alumbrado Exterior para la Protección del Medio Ambiente mediante la mejora de la Eficiencia Energética, Instituto para la Diversificación y Ahorro de la Energía, Madrid, 2002, p. 17).

57 Vid. al respecto el apartado IV de este trabajo.

58 Propuesta de Modelo de Ordenanza Municipal..., cit., p. 17.

59 Propuesta de Modelo de Ordenanza Municipal..., cit., p. 17.
} 
normas autonómicas aprobadas hasta el momento. En ellas, como veremos, se recogen amplias competencias de los municipios y su actuación a través de múltiples instrumentos de intervención.

\section{Los fines que deben orientar la actuación de los municipios sobre la contaminación lumínica}

Expuestas las competencias que justifican la actuación de los municipios sobre la contaminación lumínica, deben ponerse de manifiesto ahora los fines que deben perseguir los ayuntamientos en su actuación de ordenación, intervención y control de la iluminación en aras a reducir los negativos efectos desatados por la contaminación lumínica ${ }^{60}$.

En primer lugar, los municipios deben promover y facilitar la eficiencia energética de los alumbrados exteriores mediante el ahorro de energía, para evitar el problema del despilfarro energético, económico y la contaminación lumínica causados por una inadecuada iluminación. Todo ello sin perjuicio de garantizar la seguridad de los usuarios y la visibilidad ${ }^{61}$. La consecución de esta finalidad exigirá disponer de instalaciones de alumbrado eficiente y realizar las inversiones necesarias para sustituir las luminarias que no cumplan con los criterios de eficiencia, que se amortizan en un período corto ${ }^{62}$. Será preciso, además, adecuar los requerimientos y características técnicas de las instalaciones de alumbrado exterior a las recomendaciones y normativas vigentes ${ }^{63}$.

En segundo lugar, deben perseguir el mantenimiento al máximo de las condiciones naturales de luz de las horas nocturnas, en beneficio de la flora, la fauna y de los ecosistemas en general. Se trata, como advierte JAUME FERNÁNDEZ, «de una finalidad de carácter protector del entorno natural que forma parte de las políticas de protección de los espacios y hábitats naturales» ${ }^{64}$.

\footnotetext{
60 Vid. JAUMe FERNÁNDEZ, C., «La contaminación lumínica...», cit.

${ }^{61}$ Véase el artículo 2.a) del Modelo de ordenanza de alumbrado exterior para la protección del medio ambiente mediante la mejora de la eficiencia energética, elaborada en 2002 por un grupo de trabajo formado por el Consejo Español de Iluminación y el Instituto para la Diversificación y Ahorro de Energía (IDAE)

${ }^{62}$ Sociedad de Ciencias Aranzadi (Departamento de Astronomía) y Cadem-Grupo Eve (Unidad DE TERCIARIO), Consideraciones sobre el uso racional de la energía..., cit., ponen de manifiesto que «Debido al ahorro energético que conlleva una instalación de alumbrado eficiente, la inversión necesaria para realizar los cambios orientados a corregir la iluminación se amortiza en un plazo generalmente inferior a los siete años, totalmente aceptable para una instalación que tendrá una vida útil de 25 años en promedio. Sorprendentemente, se trata del único problema medioambiental cuya solución es rentable: no implica inversiones a fondo perdido, sino que genera beneficios» (p. 32)

${ }_{63}$ Véase el artículo 2.e) del Modelo de ordenanza de alumbrado exterior para la protección del medio ambiente..., cit.

${ }^{64}$ JAUME FERNÁNDEZ, C., «La contaminación lumínica...», cit. Esta finalidad se recoge también en el artículo 2.b) del Modelo de ordenanza de alumbrado exterior para la protección del medio ambiente..., cit.
} 
EL PAPEL DE LOS MUNICIPIOS EN LA PREVENCIÓN, ORDENACIÓN Y CONTROL...

En tercer lugar, estrechamente conectada con la anterior, los municipios deben perseguir otra finalidad: la de prevenir y corregir los efectos del resplandor luminoso nocturno en la visión del cielo, para lo cual será necesario articular una serie de medidas de intervención ${ }^{65}$. Con ello, se trata de preservar el libre acceso de la mirada humana al «techo» común de la humanidad con sus destellos de belleza y de tranquilidad —utilizando palabras de JAUME FERNÁNDEZ- o - utilizando los términos empleados por SÁINZ MORENOla contemplación del cielo y, en último término, el derecho a la oscuridad natural ${ }^{66}$.

En cuarto lugar, la actuación municipal debe orientarse a evitar o, en su caso, minimizar la intrusión luminosa en el entorno doméstico y, por tanto, disminuir sus molestias y perjuicios ${ }^{67}$. Es evidente que una iluminación excesiva, la incorrecta orientación de las luminarias urbanas o los potentes rótulos luminosos que iluminan algunos paneles publicitarios ubicados en espacios públicos o determinados establecimientos pueden provocar la intrusión de la luz artificial procedente de la calle en las viviendas y con ello una intromisión en la vida privada de las personas afectadas, pudiendo llegar, incluso a ocasionar daños a la salud. De ahí que sea del todo necesario compatibilizar la iluminación de edificios singulares, calles, establecimientos... con el respeto de las personas que viven en su entorno ${ }^{68}$. Ésta es además, la posición asumida por la jurisprudencia, tanto del Tribunal Europeo de Derechos Humanos - paradigmáticas son en este sentido las Sentencias de 9 de diciembre de 1994, López Ostra contra España y de 16 de noviembre de 2004, Moreno Gómez contra España-, como por los tribunales internos, en relación con la contaminación acústica y las intromisiones producidas por ruidos excesivos.

\footnotetext{
${ }^{65}$ Véase el artículo 2.c) del Modelo de ordenanza de alumbrado exterior para la protección del medio ambiente..., cit.

${ }^{66}$ Sainz Moreno, F., «La protecció de l'atmosfera», en el libro colectivo coordinado por María Jesús Montoro Chiner, Estudis de Dret Ambiental, Departament de Medi Ambient, Generalitat de Catalunya, Barcelona, 1995, p. 180.

${ }^{67}$ Véase el artículo 2.d) del Modelo de ordenanza de alumbrado exterior para la protección del medio ambiente..., cit.

${ }^{68}$ Así lo pone de manifiesto Calvo Charro, M., «La contaminación lumínica...», cit., pp. 37-40. Esta autora también ha defendido la inclusión, dentro del derecho a un medio ambiente adecuado y del concepto de medio ambiente, reconocido en el artículo 45 de la Constitución Española, del derecho a un cielo oscuro (vid. pp. 27 a 36). Señala CAlvo ChARro, M., «La contaminación lumínica...», cit., que «si es objeto merecedor de protección la belleza paisajística que contemplamos bajo la luz del sol, ¿por qué no ha de serlo en idéntica medida la belleza que nos ofrece la noche, el paisaje nocturno y el resplandor de sus astros? Para ello, para garantizar un derecho al medio ambiente nocturno que se traduzca en el derecho a la observación de la noche estrellada, es imprescindible favorecer la existencia de un cielo oscuro y, en consecuencia, la ausencia de contaminación lumínica» (pp. 30-31).
} 


\section{Las posibles acciones de los municipios para la prevención, ordenación y control de la contaminación lumínica}

Enmarcadas las competencias de los municipios en materia de contaminación lumínica y puestos de relieve los fines que deben orientar su actuación en este ámbito, deben plantearse a continuación acciones concretas o instrumentos de prevención, ordenación y control potencialmente utilizables desde este nivel administrativo para poner freno a esta problemática ambiental. A esta labor se dedican los apartados siguientes, no sin antes advertir que estamos ante una materia esencialmente local, en el sentido que deben ser los propios municipios - y cualesquiera otros entes locales- actores principales que impulsen las políticas de minimización y erradicación de la contaminación lumínica ${ }^{69}$, sin perjuicio de que también deban ser adoptadas determinadas medidas desde otros niveles superiores.

\subsection{La aprobación de ordenanzas municipales}

Como ya señalamos, la LBRL reconoce como competencias propias de los municipios la protección del medio ambiente y el alumbrado público, configurándose además estas materias como servicios públicos obligatorios que deben prestar los municipios de más de 50.000 habitantes —en el primer caso- y todos ellos —en el segundo- . Estas competencias, unidas a la atribución de la potestad reglamentaria a los municipios - también a las provincias y a las islas- dentro de la esfera de sus competencias, que efectúa el artículo 4.1.a) de la LBRL, justifican la aprobación de ordenanzas locales con el fin de prevenir, ordenar y controlar el fenómeno de la contaminación lumínica, para mejorar la protección del medio ambiente, mediante el aumento de la eficiencia energética de las instalaciones de alumbrado. Estas ordenanzas suelen regular las condiciones a cumplir por las instalaciones de alumbrado exterior del municipio y establecen también otros mecanismos de prevención y control de la contaminación lumínica —como la zonificación, las ayudas y subvenciones...- con el fin de mejorar la protección del medio ambiente, un uso eficiente y racional de la energía consumida y la reducción del resplandor luminoso nocturno.

La importancia de estas ordenanzas en la materia objeto de estudio es fundamental. Por una parte, en la medida en que aún no existe una legislación estatal básica al respecto y en la gran mayoría de comunidades autónomas tampoco hay todavía legislación específica — salvo los casos ya comentados de Cataluña, Islas Baleares, Navarra y Cantabria-, la aprobación de estas ordenanzas por parte de los municipios constituye, en muchas ocasiones, la única normativa en la materia, como también ha sucedido durante muchos años en otros subsectores ambientales —el de la contaminación acús-

\footnotetext{
${ }^{69}$ Así lo advierte JaUme FernándeZ, C., «La contaminación lumínica...», cit.
} 
EL PAPEL DE LOS MUNICIPIOS EN LA PREVENCIÓN, ORDENACIÓN Y CONTROL...

tica es un ejemplo paradigmático- ${ }^{70}$. La aprobación de ordenanzas en esta materia se considera tan relevante para poner freno al uso indiscriminado de las emisiones de luz nocturnas que la Estrategia de Ahorro y Eficiencia Energética en España 2004-2012, aprobada el 28 de noviembre de 2003, prevé, entre los instrumentos para superar los obstáculos y conseguir la implantación de las medidas técnicas en el subsector de alumbrado público, «el desarrollo y aprobación de una «Ordenanza Municipal de Alumbrada Exterior para la Protección del Medio Ambiente mediante la mejora de la Eficiencia Energética», coordinada con la normativa autonómica y estatal, dentro del ámbito de sus competencias en materia de alumbrado público, como es la Ley Reguladora de Bases del Régimen Local» ${ }^{71}$.

Por otra, aun existiendo normativa autonómica al respecto, no debe menospreciarse el valor de las ordenanzas, toda vez que permiten fijar y concretar el contenido de la regulación general en el ámbito municipal y adaptarlo a sus necesidades y peculiaridades. Además, sin vulnerar los mínimos contenidos en esta legislación autonómica, los municipios podrán establecer normas de protección ambiental más rigurosas ${ }^{72}$. La configuración del ordenamiento jurídico ambiental permite, así, que cada escalón inferior pueda añadir un plus de protección al establecido por el escalón inmediatamente superior. Desde esta perspectiva, las comunidades autónomas podrían reforzar la protección ambiental mínima establecida por el Estado y los municipios la fijada por la comunidad autónoma. En definitiva, como ha puesto de manifiesto CHOY TARRÉs, "com més proper al ciutadà estigui situat el poder públic més rigorós pot ser aquest en la protecció del medi, respectant sempre, però, els interessos generals de major abast territorial que siguin concurrents» ${ }^{73}$. En consecuencia, «en virtut del caràcter de legislació de mínims que té el dret ambiental, que atorga als ens locals la potestat d'establir mesures addicionals o complementàries de protecció del medi, és en aquest

\footnotetext{
70 Téngase en cuenta que «La concurrencia de competencias del Estado, Comunidades Autónomas y Corporaciones Locales en esta materia de protección del medio ambiente no impide que el municipio pueda desarrollar sus funciones de modo autónomo (art. 137 de la Constitución). De este modo, como vienen reconociendo doctrina y jurisprudencia - ejemplo la Sentencia del Tribunal Supremo de 14 de enero de 1998, Ar. 561-, sin necesidad de que una ley sectorial estatal o autonómica le autorice expresamente, el municipio puede ejercer su función normativa en los ámbitos materiales de su competencia conforme a la legislación básica de régimen local, Ley 7/1985» (Propuesta de Modelo de Ordenanza municipal de alumbrado exterior para la protección del medio ambiente mediante la mejora de la eficiencia energética, IDAE, Madrid, 2002, p. 17).

71 Estrategia de Ahorro y Eficiencia Energética en España 2004-2012, Ministerio de Economía, 5 de noviembre de 2003 , p. 22 . Puede consultarse en la siguiente página web: http://mityc.es/NR/rdonlyres/ 0527323B-D56F-4218-BF30-15E21BF01A14/0/AprobacionEstrategia.pdf (último acceso el día 20 de marzo de 2007).

${ }^{72}$ En este sentido, al analizar la potestad normativa local en materia de medio ambiente, MALARET García, E., Pérez Velasco, M. y Conde CASTEjón, J., «La regulación municipal del medio ambiente y la industria», en la obra colectiva coordinada por José EsTEve PARDo, Derecho del Medio Ambiente y Administración Local, Civitas-Diputación de Barcelona, Madrid, 1996, p. 146.

73 ChOy TARrés, A., La conflictivitat competencial. Medi ambient, Institut d'Estudis Autonòmics de la Generalitat de Catalunya, Barcelona, 1994, p. 27.
} 
camp on els ens locals disposen d'un marge d'acció legislativa autònoma $\gg^{74}$. Y ello nos debe llevar a admitir que los municipios puedan elaborar políticas ambientales propias, por ejemplo, en el ámbito que centra nuestra atención. Así lo ha puesto de relieve Alonso GaRCíA: «Aunque no haya constancia expresa en ningún texto normativo del principio de que los municipios pueden optar por modelos de mayor protección del medio ambiente, de hecho cabe entender que pueden hacerlo aunque ello conlleve la tensión constante con el modelo autonómicolestatal/supranacional e internacional de la política ambiental correspondiente. Los municipios, todos ellos, pueden poner en marcha políticas ambientales propias, y otra cosa es que su plasmación concreta tenga que defenderse, en una dinámica o dialéctica constante, frente a las decisiones de otros poderes» ${ }^{75}$.

Esta posibilidad de que las ordenanzas municipales puedan reforzar la protección establecida por la normativa autonómica ha sido recogida expresamente en la Ley 6/2006, de 9 de junio, de prevención de la contaminación lumínica de Cantabria. En efecto, su artículo 7.4 reconoce expresamente que

«Los Ayuntamientos podrán elevar el nivel de protección previsto mediante ordenanzas aprobadas al efecto o, en su caso, en las correspondientes normas del planeamiento urbanístico, bien zonificando con criterios propios el suelo urbano y urbanizable, bien mejorando los niveles de protección aprobados por la Comunidad Autónoma, que tendrán siempre el carácter de mínimos».

Y su artículo 8.3 permite que los ayuntamientos puedan elevar el nivel de protección fijado a nivel autonómico (en cuanto a los niveles máximos de luz, las prescripciones técnicas que deban satisfacer las instalaciones y aparatos de iluminación para evitar la contaminación lumínica; las prescripciones técnicas exigibles a las instalaciones y aparatos de iluminación por motivos de eficiencia energética; las condiciones mínimas de mantenimiento y conservación de las instalaciones y aparatos de mantenimiento; y las condiciones para la instalación y funcionamiento de alumbrados que funcionen en horario nocturno), mediante las oportunas previsiones incorporadas a sus reglamentos y ordenanzas, así como a las determinaciones y normas de su planeamiento urbanístico. Ahora bien, en ningún caso, estas prescripciones municipales podrán reducir los niveles de protección determinados por la comunidad autónoma.

Para facilitar la adopción de ordenanzas municipales en materia de contaminación lumínica, el Comité Español de Iluminación (en adelante, CEI)

\footnotetext{
74 ChOy TARrés, A., La conflictivitat competencial..., cit., p. 105.

75 Alonso García, E., «La gestión del medio ambiente por las entidades locales», en la obra colectiva dirigida por Santiago MuÑoz Machado, Tratado de Derecho Municipal, vol. II, $2^{\text {a }}$ edición, ThomsonCivitas, Madrid, 2003, p. 1826. En esta línea, el nuevo Estatuto de Autonomía de Cataluña incluye entre las competencias propias de los gobiernos locales de Cataluña, en los términos que determinen las leyes, «La formulación y la gestión de políticas para la protección del medio ambiente y el desarrollo sostenible» [art. 84.2.j)].
} 
y el Instituto para la Diversificación y Ahorro de la Energía (en adelante, IDAE) han elaborado una Propuesta de modelo de Ordenanza municipal de alumbrado exterior para la protección del medio ambiente mediante la mejora de la eficiencia energética ${ }^{76}$, destinada a aquellos Ayuntamientos que quieren regular sus instalaciones de alumbrado exterior, tanto público como privado, para reducir el impacto medioambiental en cuanto a consumo de energía y resplandor luminoso nocturno ${ }^{77}$.

Este modelo de ordenanza pretende «servir de orientación y apoyo a los Ayuntamientos para que regulen las instalaciones de alumbrado exterior desde el punto de vista de la protección del medio ambiente, mediante un uso eficiente y racional de la energía, así como una reducción del resplandor luminoso nocturno, al objeto de coadyuvar en el logro de ciudades sostenibles $»^{78}$. Asimismo, pretende «dar un respaldo jurídico y establecer las «reglas de juego» que permitan conocer tanto a cualquier persona física o jurídica, entidad y organismo oficial a cuya iniciativa se ejecuten este tipo de instalaciones, como al administrador - el Ayuntamiento-, cuál es el marco de obligaciones y derechos en que deben moverse, con el fin de que las instalaciones de alumbrado exterior se ejecuten, exploten y mantengan eficiente

\footnotetext{
${ }^{76}$ Propuesta de Modelo de Ordenanza municipal de alumbrado exterior..., cit. Esta publicación ha sido elaborada por el Grupo de Trabajo formado por el CEI y el IDAE, con el asesoramiento legal de los profesores Alfredo Gallego Anabitarte y Julia Ortega Bernardo, del Área de Derecho Administrativo de la Facultad de Derecho de la Universidad Autónoma de Madrid.

${ }^{77}$ El origen de esta Propuesta de Modelo de Ordenanza municipal se encuentra en la Proposición no de Ley relativa a la iluminación nocturna de pueblos y ciudades, presentada por el Grupo Parlamentario Popular en el Congreso (Boletín Oficial de las Cortes Generales, Congreso de los Diputados, serie D, núm. 493, de 25 de octubre de 1999) y aprobada, en sus propios términos, por la Comisión de Industria, Energía y Turismo, en su sesión del día 27 de octubre de 1999 (Boletín Oficial de las Cortes Generales, Congreso de los Diputados, serie D, núm. 500, de 8 de noviembre de 1999). En ella, el Congreso de los Diputados instaba al Gobierno a llevar a cabo las siguientes actuaciones, a través del IDAE:
}

1. Analizar las características idóneas de la iluminación urbana, elaborando una guía al respecto siguiendo las recomendaciones de la Comision Internationale de L'Eclariage (CIE) y del CEI, ampliando sus propias guías CEI-IDAE de 1996. En estas guías, además de analizar los aspectos teóricos de la adecuada iluminación urbana, deben de analizarse las luminarias más utilizadas habitualmente analizando sus ventajas e inconvenientes, eficiencia energética y contaminación lumínica que provocan.

2. Diseñar un programa de información y difusión a los Ayuntamientos de los trabajos anteriores y de asesoramiento sobre la iluminación urbana.

3. Diseñar un programa de apoyo económico para los Ayuntamientos destinado al cambio de los actuales sistemas de iluminación urbana por otros más eficientes y que provoquen menor contaminación lumínica. Los fondos de este programa serían adelantados por el IDAE y se recuperarían con los ahorros de la factura energética que produjeran en los distintos Ayuntamientos. En consecuencia, las actuaciones podrían autofinanciarse, tras una aportación pública inicial.

Para dar respuesta a esta demanda se han llevado a cabo diferentes actuaciones, como un convenio de colaboración entre el CEI y el IDAE, fruto del cual se elaboró una Guía para la eficiencia energética en el alumbrado público, una línea de financiación para el fomento de las inversiones en energías renovables y eficiencia energética y la Propuesta de ordenanza municipal a que nos venimos refiriendo.

78 Propuesta de Modelo de Ordenanza municipal de alumbrado exterior..., cit., p. 12. 
y correctamente, con criterios de protección del medio ambiente y con las debidas garantías de seguridad y calidad para la población en general ${ }^{79}$.

Esta Ordenanza tiene por objeto establecer las condiciones que deben cumplir las instalaciones de alumbrado exterior, tanto públicas como privadas, situadas en el término municipal, con el fin de mejorar la protección del medio ambiente mediante un uso eficiente y racional de la energía que consumen y la reducción del resplandor luminoso nocturno, sin menoscabo de la seguridad, de los peatones y propiedades, que deben proporcionar dichas instalaciones (art. 1). Para ello, será de aplicación a los proyectos, memorias técnicas de diseño y obras de alumbrado exterior, tanto públicos como privados, de nuevas instalaciones, así como de los proyectos de remodelación o ampliación de las existentes (art. 3) ${ }^{80}$.

Entre las medidas más importantes que incorpora esta Propuesta de Ordenanza, cabe destacar la zonificación del término municipal en zonas E1, E2, E3 y E4; el establecimiento de los requisitos técnicos que deberán cumplir las instalaciones de alumbrado exterior; la fijación de valores límite del flujo de hemisferio superior instalado; de las características fotométricas de los pavimentos; el establecimiento del régimen estacional y horario de usos del alumbrado exterior; la determinación de las características que deben reunir determinados alumbrados (vial, de túneles y pasos inferiores, de aparcamientos al aire libre, de fachadas de edificios y monumentos, de instalaciones deportivas y recreativas exteriores, de áreas de trabajo exteriores, de seguridad, de carteles y anuncios luminosos, de escaparates y festivo y navideño); medidas de mantenimiento de las instalaciones; de garantía del cumplimiento de esta ordenanza en instalaciones privadas y públicas; y facultades de inspección y control; y régimen sancionador.

Se trata, en definitiva, de un modelo de ordenanza de alumbrado exterior para la protección del medio ambiente, mediante la mejora de la eficiencia energética, al alcance de los ayuntamientos, que puede facilitarles la aprobación de ordenanzas y la intervención en esta materia, en aras de una mejor protección ambiental y eficiencia energética. Sería necesario, sin embargo, intensificar la información sobre la existencia de este modelo, dado el grado de desconocimiento que presentan muchos municipios ${ }^{81}$.

\footnotetext{
79 Vid. la motivación de la necesidad de esta Propuesta de Modelo de Ordenanza municipal. Propuesta de Modelo de Ordenanza municipal de alumbrado exterior..., cit., p. 12.

${ }^{80}$ Se excluyen, sin embargo, de su ámbito de aplicación los puertos, aeropuertos, líneas de ferrocarril, instalaciones militares y de seguridad ciudadana... y, en general, aquellas instalaciones de competencia exclusiva estatal o autonómica; cualquier otra instalación que la legislación y, en su caso, planificación estatal o autonómica establezcan como excepción a los sistemas de alumbrado; y cualquier instalación de alumbrado que se considere accesoria a obras de interés general, estatal o autonómica, o a una actividad de su competencia. Sobre la justificación de estas exclusiones, vid. Propuesta de Modelo de Ordenanza municipal de alumbrado exterior..., cit., pp. 17-18.

${ }^{81}$ Sólo una tercera parte de los ayuntamientos tiene información sobre la existencia de modelos que les ayuden en la realización de una ordenanza de alumbrado exterior. Vid. Situación de las ordenanzas solar y de alumbrado exterior en España, Madrid, 26 de mayo de 2003, IDAE y FEMP, pp. 10-12.
} 
EL PAPEL DE LOS MUNICIPIOS EN LA PREVENCIÓN, ORDENACIÓN Y CONTROL...

De todas formas, pese a las virtualidades que presentan las ordenanzas locales como instrumento esencial para luchar contra la contaminación lumínica «no son sin embargo suficientes para poner fin al problema; no sólo por su limitado ámbito geográfico de aplicación, sino también por la inexistencia de una obligación general de que los ayuntamientos las aprueben ${ }^{82}$. Además, aún son pocos los municipios que disponen de estas ordenanzas ${ }^{83}$. De ahí la importancia de que exista una regulación general en esta materia a nivel estatal o, por lo menos autonómico. Por otra parte, también debe destacarse que algunos municipios, aun sin haber aprobado una ordenanza reguladora de la contaminación lumínica, han tenido una actuación ejemplar al respecto $^{84}$.

\subsection{La adopción de medidas sobre las instalaciones de alumbrado e iluminación exterior}

Los municipios también pueden intervenir sobre las instalaciones de alumbrado e iluminación exterior, con la finalidad de mejorar la protección del medio ambiente, mediante el aumento de la eficiencia energética de estas instalaciones. Desde esta perspectiva, son muchas las posibilidades de actuación que se abren para estas administraciones. En primer lugar, pueden actuar «por una parte, sobre los propios aparatos (luminarias y proyectores) que emiten la luz y, por otra, sobre la instalación de alumbrado diseñándola de forma eficiente, para que ilumine únicamente las superficies deseadas y faculte alcanzar los niveles luminosos necesarios sin superarlos, adoptando en lo posible unos tipos de pavimentos de las calzadas que permitan unas luminancias suficientes con los valores mínimos de iluminancia (relación luminancia/iluminancia lo más elevada posible). Todo ello en beneficio de un uso eficiente y racional de la energía que mejorará la protección del medio ambiente» ${ }^{85}$.

\footnotetext{
82 Sociedad de Ciencias Aranzadi (Departamento de Astronomía) y Cadem-Grupo Eve (Unidad DE TERCIARIO), Consideraciones sobre el uso racional..., cit., p. 34.

${ }^{83} \mathrm{El}$ estudio Situación de las ordenanzas solar y de alumbrado exterior en España, realizado por el IDAE y la Federación Española de Municipios y Provincias (FEMP) muestra la situación de las ordenanzas energéticas en España en el primer trimestre del año 2003 y permite realizar una primera aproximación a esta situación a partir de las respuestas recibidas de una encuesta enviada por correo y dirigida a los responsables de medio ambiente de los 323 ayuntamientos de más de 20.001 habitantes. En él se pone de manifiesto, a partir del análisis de las respuestas recibidas vía cuestionario escrito correctamente cumplimentado que sólo un 2,2\% de ayuntamientos tienen una ordenanza de alumbrado exterior; un $1,5 \%$ la tienen en tramitación; y un 6,2\% la tienen en estudio. En resumen, un 9,9\% de los ayuntamientos españoles de más de 20.001 habitantes tienen ordenanzas aprobadas, en tramitación o en estudio. Un 14,2 \% del ayuntamientos la considerarán en un futuro. Lo que representa que casi una cuarta parte, un $24.1 \%$ de los ayuntamientos españoles, están interesados en la vía de las ordenanzas de alumbrado exterior. Vid. Situación de las ordenanzas solar y de alumbrado exterior en España, Madrid, 26 de mayo de 2003, IDAE y FEMP, pp. 9-11.

${ }^{84}$ Éste es el caso, por ejemplo, de Figueres (en Cataluña), a partir de la elaboración, en el año 1995, de un Plan director del alumbrado público.
}

${ }^{85}$ Propuesta de Modelo de Ordenanza municipal de alumbrado exterior..., cit., p. 12 
En segundo lugar, también pueden intervenir mediante el establecimiento de un régimen de funcionamiento y horario del alumbrado, lo que implica regular adecuadamente el apagado y encendido de las instalaciones de alumbrado exterior e incluso implantar un sistema de regulación del nivel luminoso con disminución del flujo emitido en determinadas franjas horarias, siempre que se garantice la seguridad de los ciudadanos; el ajuste de los niveles de iluminación en el suelo a los recomendados por la Comisión Internacional de Iluminación; la utilización de lámparas poco contaminantes y de gran eficiencia energética... Se trata de reordenar la iluminación y el alumbrado exterior, tanto de propiedad pública como privada, con la finalidad de obtener una distribución más efectiva y eficiente de la luz, utilizarla en la cantidad mínima necesaria... ${ }^{86}$

En tercer lugar, debe mencionarse la intervención municipal sobre las instalaciones de alumbrado exterior. Si bien estas instalaciones son obras tanto de ejecución municipal como de iniciativa particular, es competencia de los ayuntamientos «la concesión de la oportuna licencia o autorización que precisa su ejecución para que, una vez finalizadas, las reciba para su explotación y mantenimiento, pero solo aquellas instalaciones que por su implantación en zonas o vías públicas le correspondan, mientras que el resto de instalaciones de indole privada o cuya gestión sea competencia de otros organismos, serán explotadas y mantenidas por los titulares de las mismas ${ }^{87}$. Las licencias constituyen, de este modo, un instrumento idóneo para comprobar el cumplimiento de los requisitos lumínicos establecidos por la normativa autonómica o local —si existe- ${ }^{88}$.

Por último, una medida de gran envergadura que debieran acometer los municipios (así como otras instituciones públicas) en este ámbito, para asegurar una adecuada protección ambiental y aumentar la eficiencia energética, es la de promover la renovación de las instalaciones de alumbrado público exterior existentes, con el fin de reducir el consumo de energía. Esta medida pretende renovar las instalaciones de alumbrado público exterior existentes aplicando criterios de ahorro y eficiencia energética ${ }^{89}$ y resulta

\footnotetext{
${ }^{86}$ En la Estrategia de Ahorro y Eficiencia Energética en España 2004-2012, cit., p. 20, se prevén entre las medidas a adoptar en el subsector de alumbrado público — dentro de los servicios públicos-, la sustitución de lámparas de vapor de mercurio; la sustitución de luminarias por otras con mayor rendimiento y lámparas de menor potencia; la instalación de sistemas de regulación del nivel luminoso; la instalación de reloj astronómico programable en cada cuadro de alumbrado, con el fin de ajustar mejor el encendido/apagado y reducir las horas de encendido; y la sustitución de semáforos que utilicen tecnología convencional por otros que utilicen tecnología LED.

${ }^{87}$ Propuesta de Modelo de Ordenanza municipal de alumbrado exterior..., cit., p. 12

88 Vid. infra el apartado IV.4 de este trabajo. La Propuesta de Modelo de Ordenanza municipal de alumbrado exterior..., cit., p. 12, señala que "De esta exigencia de licencia municipal se excluyen las instalaciones de alumbrado público, en la medida que el que este tipo de instalaciones cumplan las previsiones de la Ordenanza sobre contaminación lumínica es una cuestión que atañe exclusivamente al municipio que decide aprobar dicha Ordenanza».

${ }^{89}$ En el marco de la Estrategia de Ahorro y Eficiencia Energética en España 2004-2012, el Plan de Acción 2005-2007, aprobado por el IDAE el 6 de julio de 2005, prevé entre las medidas a adoptar para
} 
EL PAPEL DE LOS MUNICIPIOS EN LA PREVENCIÓN, ORDENACIÓN Y CONTROL...

fundamental en esta materia, habida cuenta que los municipios (y otras administraciones públicas) son un importante consumidor de energía y a ellos les corresponde también una función ejemplarizante. También es importante mejorar la eficiencia energética de las nuevas instalaciones de alumbrado público exterior ${ }^{90}$, así como impulsar la realización de auditorías energéticas en los edificios municipales o en las zonas y espacios públicos, con el objetivo de fomentar el ahorro de energía ${ }^{91}$. La realización de todas estas actuaciones, especialmente la adaptación de las instalaciones existentes a los nuevos parámetros de eficiencia energética, requerirá importantes inversiones por parte de la administración local, propietaria de la mayoría de las instalaciones de alumbrado público, sin perjuicio de que pueda contar para ello con líneas de apoyo económico ${ }^{92}$. De todas formas, la inversión puede ser recuperada en un período corto de tiempo en función de los ahorros energéticos y económicos conseguidos durante el período de vida de la instalación.

\subsection{La zonificación y la planificación}

Otro de los instrumentos de intervención de que disponen los municipios para intervenir en materia de contaminación lumínica es el de la zonificación de áreas luminosas, en función de su vulnerabilidad, dentro de su término municipal, de acuerdo con los criterios que en cada caso establezca la legislación autonómica — si existe— ${ }^{93}$, a los efectos de establecer diferentes zonas afectadas por la contaminación lumínica y corregir el impacto de la misma sobre las personas y el medio ambiente. La zonificación se incluye en la gran mayoría de ordenanzas aprobadas hasta la fecha. Asimismo, la Propuesta de modelo de Ordenanza municipal de alumbrado exterior para la protección del medio ambiente mediante la mejora de la eficiencia energética a la que nos hemos referido con anterioridad prevé, en su artículo 5, la zonificación del término municipal en función del siguiente criterio de clasificación:

\footnotetext{
el sector servicios públicos las de promover la renovación de las instalaciones de alumbrado público exterior existentes; y la creación de un programa para la realización de estudios, análisis de viabilidad $\mathrm{y}$ auditorías en instalaciones de alumbrado exterior existentes.

90 Entre las medidas urgentes a adoptar en el sector servicios públicos, el Plan de Acción 2005-2007 (en el marco de la Estrategia de Ahorro y Eficiencia Energética en España 2004-2012), IDAE, 6 de julio de 2005, prevé la mejora de la eficiencia energética de la nuevas instalaciones de alumbrado público exterior y de las instalaciones actuales de alumbrado público exterior. Concretamente, establece que «se han priorizado las actuaciones sobre el alumbrado público exterior, no sólo por el carácter de las actuaciones —de tipo legislativo y normativo aun con otras medidas de impulso-, sino por la función ejemplarizante que pueden desempeñar las Corporaciones Locales al actuar sobre las instalaciones bajo su competencia. Dado que se distingue entre la mejora de la eficiencia que puede conseguirse en instalaciones nuevas y, separadamente, en instalaciones existentes, se concede la máxima prioridad a las actuaciones sobre las instalaciones nuevas. La mayor facilidad de actuar sobre las nuevas instalaciones, mediante la aprobación de la normativa reguladora adecuada —normalmente, bajo la forma de ordenanzas municipales- ha justificado esta decisión» (p. 210).

91 JAUME FERNÁNDEZ, C., «La contaminación lumínica...», cit.

92 Vid. infra, el apartado III.4 de este estudio.

93 Vid. infra, el apartado IV.1 de este estudio.
} 
- E1: áreas con entornos oscuros como parques nacionales y áreas de notable belleza natural (donde las carreteras están sin iluminar).

- E2: áreas de bajo brillo, generalmente fuera de las áreas residenciales urbanas o industriales (donde las carreteras están iluminadas).

- E3: áreas de brillo medio; normalmente residenciales urbanas (donde las carreteras están iluminadas según las normas para calzadas con mucho tráfico).

- E4: áreas de brillo alto; genéricamente, áreas urbanas que incluyen zonas residenciales y para usos comerciales con una elevada actividad durante la franja horaria nocturna).

También la planificación urbanística puede ser un instrumento idóneo en aras a la protección del medio ambiente frente a la contaminación lumínica, si se incluyen en los instrumentos de planeamiento medidas relativas al alumbrado público ${ }^{94}$. Recuérdese que, en gran medida, son los municipios los competentes para implantar el alumbrado o imponer sus características en el planeamiento urbanístico.

\subsection{Otras medidas}

Junto a las medidas anteriores, también cobran gran relevancia las medidas de educación ambiental y la realización de campañas de información y sensibilización ciudadana, con el fin de dar a conocer la problemática de la contaminación lumínica, los efectos nocivos de una incorrecta e inadecuada iluminación y los medios para evitarlos o minimizarlos y fomentar conductas positivas de la ciudadanía. También la habilitación de fondos públicos con la finalidad de contribuir a la implementación de políticas de protección y corrección frente a la contaminación lumínica.

\section{La necesaria colaboración de las administraciones supramunicipales}

A la vista de lo expuesto, se desprende fácilmente la importancia de la actuación municipal en relación con la prevención de la contaminación lumínica. Nos hallamos ante una materia en la que resulta decisiva la intervención municipal para impulsar políticas de minimización y erradicación de la contaminación lumínica y de ahorro y eficiencia energética ${ }^{95}$. Sin embargo, también en esta materia resulta fundamental la intervención de otras admi-

\footnotetext{
94 Vid. infra, el apartado IV.2 de este estudio.

95 Así lo pone de manifiesto JAUME FernÁNDEZ, C., «La contaminación lumínica...», cit., en cuya opinión se trata de una materia esencialmente local.
} 
EL PAPEL DE LOS MUNICIPIOS EN LA PREVENCIÓN, ORDENACIÓN Y CONTROL...

nistraciones supramunicipales. Desde esta perspectiva, las Comunidades Autónomas deben, en el ámbito de sus respectivas competencias, impulsar la colaboración con los municipios para reducir el impacto negativo de la contaminación lumínica ${ }^{96}$. En esta línea, las leyes autonómicas hasta ahora aprobadas prevén expresamente la colaboración de la Administración autonómica con los ayuntamientos ${ }^{97}$, articulan —a excepción de Navarra- un fondo económico de carácter autonómico para la prevención de la contaminación lumínica y la mejora de la eficiencia energética ${ }^{98}$ y un régimen de ayudas específicas para promover la adaptación de los alumbrados exteriores a las prescripciones normativas ${ }^{99}$.

También el Plan de Acción 2005-2007 (en el marco de la Estrategia de Ahorro y Eficiencia Energética en España 2004-2012), adoptado por el IDAE, prevé que la implementación de las medidas prioritarias incluidas en el sector servicios públicos (entre las que se incluye la mejora de la eficiencia energética de las instalaciones actuales de alumbrado exterior) ${ }^{100}$ exigirá una intervención activa de la Administración General del Estado y de las Comunidades Autónomas. Concretamente, prevé que en todas las medidas establecidas la Administración General del Estado debe ser la iniciadora y propulsora de las actuaciones propuestas, si bien «es fundamental que se establezca un marco adecuado de cooperación entre las Administraciones implicadas y, en particular, con las Comunidades Autónomas. La Administración General del Estado debe impulsar las actuaciones y definir el marco general de desarrollo de las mismas, así como promover acuerdos específicos con las Comunidades Autónomas y las Administraciones Locales» ${ }^{101}$. Asimismo, prevé la participación de las Comunidades Autónomas en la implementación de

\footnotetext{
96 JAUME FERNÁNDEZ, C., «La contaminación lumínica...», cit., considera que, en este sentido, "pueden establecerse diferentes mecanismos o instrumentos para asegurar la intervención de la Administración autonómica en este ámbito. Por ejemplo, un primer instrumento lo constituye la habilitación de fondos públicos con la finalidad de implementar las políticas de protección y de corrección de este tipo de contaminación. Un segundo instrumento lo constituye el ejercicio de las competencias de inspección y de control -y en consecuencia de sanción- sobre los titulares de las instalaciones — públicas o privadas-ubicadas en el territorio de su respectiva Comunidad Autónoma. Y finalmente, un tercer instrumento de participación autonómica en este ámbito, puede venir dado por la previsión normativa autonómica de exigir la presentación de proyectos técnicos específicos sobre iluminación cuando deban estas administraciones autorizar determinadas actividades o instalaciones o celebrar contratos de obra pública con particulares».

97 Véase la disposición transitoria $2^{\text {a }}$ de las Leyes 6/2001 de Cataluña, 3/2005 de Baleares, 10/2005 de Navarra y 6/2006 de Cantabria. Esta última también prevé que «De acuerdo con el principio de colaboración, se promoverán convenios de colaboración entre la Administración autonómica y las Administraciones locales, así como, si procede, con la Administración General del Estado y sus organismos, para impulsar la implantación de las medidas que regula la presente Ley» (disposición final 2a).

98 Véanse los artículos 13 de la Ley 6/2001 de Cataluña, 15 de la Ley 3/2005 de Baleares y 14 de la Ley 6/2006 de Cantabria.

99 Véanse los artículos 14 de la Ley 6/2001 de Cataluña, 16 de la Ley 3/2005 de Baleares, 15 de la Ley 10/2005 de Navarra y 15 de la Ley 6/2006 de Cantabria.

100 Vid. supra el apartado III.3.2 de este artículo.

101 Plan de Acción 2005-2007, aprobado por el IDAE el 6 de julio de 2005, p. 229.
} 
la medida de mejora de la eficiencia energética de las instalaciones actuales de alumbrado exterior, incluida en el Plan, mediante la gestión de las ayudas públicas para la ejecución de proyectos.

En otro orden de cosas, no puede obviarse el peso decisivo que en esta materia también pueden jugar otras administraciones locales supramunicipales. Así, la legislación catalana, dadas las amplias competencias municipales que se derivan en este sector y la tradicional insuficiencia de muchos municipios para afrontar las competencias ambientales, atribuye un papel importante a las comarcas ${ }^{102}$.

\section{LAS COMPETENCIAS Y LAS OBLIGACIONES DE LOS MUNICIPIOS EN MATERIA DE CONTAMINACIÓN LUMÍNICA EN LA NORMATIVA AUTONÓMICA: ANÁLISIS DE LA LEGISLACIÓN CATALANA, BALEAR, NAVARRA Y CÁNTABRA}

Las normas autonómicas aprobadas hasta el momento confieren amplias competencias e imponen un buen número de obligaciones a los municipios en materia de contaminación lumínica, conscientes del relevante papel que estas administraciones pueden jugar en la prevención y control de esta nueva forma de contaminación. A continuación, se analizan las principales competencias municipales recogidas en la Ley 6/2001, de 31 de mayo, de ordenación ambiental del alumbrado para la protección del medio nocturno de Cataluña y el Decreto 82/2005, de 3 de mayo, que la desarrolla ${ }^{103}$; en la Ley $3 / 2005$, de 20 de abril, de protección del medio nocturno de las Islas Baleares; en la Ley Foral 10/2005, de 9 de noviembre, de ordenación del alumbrado para la protección del medio nocturno; y en la Ley 6/2006, de 9 de junio, de prevención de la contaminación lumínica de Cantabria.

\section{La intervención de los municipios en la zonificación}

Como ya destacamos, uno de los principales mecanismos de intervención administrativa frente a la contaminación lumínica es la zonificación del te-

\footnotetext{
${ }^{102}$ En particular, los ayuntamientos pueden delegar en los consejos comarcales la zonificación del término municipal a que les autoriza el artículo 5.3 de la Ley 6/2001, de 31 de mayo, en los términos que establece la normativa sobre régimen local (disposición adicional 4a de la Ley 6/2001). Asimismo, el Decreto 82/2005, de 3 de mayo, prevé que el Departamento de Medio Ambiente y Vivienda llevará a cabo el asesoramiento para elaborar y promover planes piloto en el ámbito comarcal de proyectos de adecuación de alumbrados existentes a sus requerimientos (disposición transitoria $2^{\mathbf{a}}$, apartado $2^{\mathbf{o}}$ ).

103 Véase el artículo 15 del Decreto catalán 82/2005, de 3 de mayo, que enumera las funciones que corresponden a los municipios en esta materia. Véanse, asimismo, los artículos 13 y 14, que recogen, respectivamente, las competencias de la Dirección General de Calidad Ambiental y de la Oficina para la Prevención de la Contaminación Luminosa, creada como área funcional adscrita a la Dirección General citada, que ejercerá las funciones previstas en el artículo 13 .
} 
EL PAPEL DE LOS MUNICIPIOS EN LA PREVENCIÓN, ORDENACIÓN Y CONTROL...

rritorio en función de su vulnerabilidad a la contaminación lumínica (zonas E1, E2, E3, E4 y puntos de referencia) ${ }^{104}$. Todas las leyes autonómicas incluyen este mecanismo, si bien remiten al posterior reglamento de desarrollo la división del territorio en estas zonas, y todas ellas reconocen facultades de actuación a los municipios. Así, facultan a los ayuntamientos para establecer una zonificación propia en su término municipal, siempre que no disminuya el nivel de protección, salvo que concurran causas justificadas, de acuerdo con lo que sea regulado por reglamento ${ }^{105}$; o los habilitan para «elevar el nivel de protección previsto mediante ordenanzas aprobadas al efecto $\mathbf{o}$, en su caso, en las correspondientes normas del planeamiento urbanístico, bien zonificando con criterios propios el suelo urbano y urbanizable, bien mejorando los niveles de referencia de cada zona», teniendo en cuenta que «en ningún caso dicha potestad municipal podrá reducir los niveles de protección aprobados por la Comunidad Autónoma, que tendrán siempre el carácter de mínimos» ${ }^{106}$.

En el caso de Cataluña, única comunidad autónoma en que se ha aprobado el reglamento de desarrollo de la ley, el Decreto 82/2005, de 3 de mayo, ha delimitado las competencias de la administración autonómica y de las administraciones locales sobre la zonificación. Con carácter general, la zonificación corresponde a la Administración de la Generalidad, sin perjuicio de la intervención de los municipios en los términos que señalamos seguidamente. En efecto, corresponde al Departamento de Medio Ambiente y Vivienda publicar, difundir y comunicar a cada ayuntamiento la zonificación de su territorio según la protección frente a la contaminación luminosa (art. 5.4 del Decreto 82/2005); y aprobar el mapa de protección frente a la contaminación luminosa en Cataluña (art. 5.5 del Decreto 82/2005) ${ }^{107}$, el cual preverá diversas zonas de protección, atendiendo, por un lado, la necesidad de mantener una correcta iluminación en aquellas áreas donde se desarrolla la actividad humana; y, por otro, la protección, tanto como sea posible, de los espacios naturales y la visión natural del cielo de noche.

\footnotetext{
104 Vid. supra apartado II.4 de este trabajo.

105 Artículos 5.3 de la Ley catalana 6/2001, de 31 de mayo; 5.3 de la Ley balear 3/2005, de 20 de abril; y 6.3 de la Ley Foral 10/2005, de 9 de noviembre.

106 Artículo 7.4 de la Ley 6/2006, de 9 de junio, de prevención de la contaminación lumínica de Cantabria.

107 Con arreglo a la disposición transitoria $1^{\text {a }}$ del Decreto 82/2005, el Departamento de Medio Ambiente y Vivienda aprobará el mapa de protección frente a la contaminación luminosa en Cataluña en el plazo máximo de dos años desde la entrada en vigor de este Decreto (entró en vigor el día 6 de mayo de 2005 - vid. su disposición final 2a -). El 21 de septiembre de 2006, el Departamento de Medio Ambiente y Vivienda presentó los mapas de zonificación de los municipios catalanes según la protección frente a la contaminación lumínica propuesta por la Generalidad. Estos mapas han sido remitidos a cada uno de los ayuntamientos catalanes, de acuerdo con las previsiones del Decreto 82/2005, de 3 de mayo, con la finalidad de que propongan las modificaciones razonadas a la zonificación de su término. El Departamento tiene previsto aprobar el mapa de protección de toda Cataluña antes de junio de 2007. En esta propuesta de zonificación se catalogan como zona E1, de máxima protección, $7.463 \mathrm{~km}^{2}(23 \%$ de Cataluña); como zona E2, de alta protección, $22.538 \mathrm{~km}^{2}$ (70\% de Cataluña); y como zona E3, de moderada protección, $2.073 \mathrm{~km}^{2}(7 \%)$. Las zonas E4 deberán determinarlas los ayuntamientos de cada municipio.
} 
A pesar de las competencias autonómicas que acaban de señalarse, las administraciones locales también tienen un cierto margen de actuación que puede reconducirse a cuatro aspectos fundamentales. En primer lugar, la determinación de las zonas E4 corresponde a los ayuntamientos, que tendrán que notificar la propuesta de zonificación al Departamento de Medio Ambiente y Vivienda, que deberá realizar la aprobación ${ }^{108}$. En segundo lugar, los ayuntamientos pueden modificar el tipo de zona de protección a la contaminación luminosa que se asigna a su término municipal, siempre y cuando eso no suponga una disminución del nivel de protección otorgado, informando a la Oficina para la Prevención de la Contaminación Luminosa (art. 5.2 del Decreto 82/2005). Asimismo, los ayuntamientos pueden proponer modificaciones razonadas a la zonificación para la protección a la contaminación luminosa en su término municipal en el plazo de un año desde la comunicación efectuada por el Departamento de Medio Ambiente y Vivienda (art. 5.4 en conexión con la disposición transitoria $1^{\mathrm{a}}$ del Decreto 82/2005). En tercer lugar, en la medida en que la iluminación en suelo urbano próximo a zonas de máxima protección (E1) o zonas acuáticas marinas y continentales debe ser especialmente respetuosa en evitar efectos perturbadores en el medio, si procede, el Departamento de Medio Ambiente y Vivienda, de acuerdo con el ayuntamiento, puede determinar características de iluminación correspondientes a zona E2 (FHS y tipo de lámpara) para garantizar una mayor protección en función de las particularidades de la zona a proteger (art. 5.3 del Decreto 82/2005). Finalmente, los ayuntamientos también intervienen en la fijación de los puntos de referencia ${ }^{109}$. Si bien su determinación corresponde al director/ a general de Calidad Ambiental ${ }^{110}$, a propuesta de la Oficina para la Prevención de la Contaminación Luminosa, los ayuntamientos o los consejos comarcales afectados cuando los ayuntamientos les hayan delegado esta atribución, deben emitir un informe preceptivo, que no se configura, sin embargo, como vinculante (art. 6.2 del Decreto 82/2005).

\section{La intervención de los municipios a través del planeamiento urbanístico}

La Ley de Cantabria 6/2006, de 9 de junio, de prevención de la contaminación lumínica recoge en su artículo 5 - bajo la rúbrica «Criterios generales de competencia municipal»- una serie de criterios que los municipios

\footnotetext{
${ }^{108}$ Artículo 5.1.d) del Decreto catalán 82/2005. Téngase en cuenta que no pueden clasificarse zonas E4 a menos de $2 \mathrm{~km}$. de una zona E1 [art. 5.1.d)].

${ }^{109}$ La disposición adicional 2 $2^{\mathrm{a}}$ del Decreto 82/2005 establece el Observatorio Astronómico del Montsec como punto de referencia. Asimismo, se define como área de influencia de este punto el territorio de los municipios del Consorcio del Montsec, el cual se considera como zona de protección E1.

${ }^{110}$ Cabe tener en cuenta que «Por cada punto de referencia situado cerca de un lugar del territorio de especial valor astronómico o natural y en función de las características y la ubicación se definirán sendas áreas de influencia. La zona E1 en torno al punto de referencia será determinada por la Oficina para la Prevención de la Contaminación Luminosa» (art. 6.1 del Decreto 82/2005).
} 
EL PAPEL DE LOS MUNICIPIOS EN LA PREVENCIÓN, ORDENACIÓN Y CONTROL...

deberán tener en cuenta en el planeamiento urbanístico. Concretamente, este precepto prevé que, en el marco de esta Ley, el planeamiento urbanístico municipal prestará especial atención a los focos emisores del alumbrado público, previendo a estos efectos entre sus determinaciones las siguientes:

a) La localización adecuada de los focos emisores de luz para la minoración de la contaminación lumínica.

b) La utilización de luminarias que cumplan los objetivos de esta Ley, el nivel lumínico de referencia que corresponda y las demás especificaciones técnicas que se aprueben.

Además, los planeamientos urbanísticos que no hayan superado la fase de aprobación provisional en el momento de la entrada en vigor de esta Ley, deberán adaptar sus determinaciones, de conformidad con la disposición adicional $1^{\mathbf{a}}$, a las previsiones de su artículo 5 . Los instrumentos de planeamiento se convierten, de este modo, en una herramienta esencial para garantizar el respeto de las prescripciones normativas en materia de contaminación lumínica $^{111}$.

\section{La intervención de los municipios sobre la iluminación exterior}

Todas las leyes autonómicas aprobadas hasta el momento contemplan ampliamente la regulación del alumbrado, si bien remiten algunos aspectos al desarrollo reglamentario (por ejemplo, la fijación de los niveles lumínicos de referencia, los niveles máximos de luz para cada uno de los usos especificados, las prescripciones técnicas aplicables a los aparatos y las instalaciones de iluminación, los criterios generales del régimen estacional y horario de usos del alumbrado exterior...). En este ámbito, también los municipios están llamados a adquirir un gran protagonismo para garantizar el cumplimiento de las prescripciones normativas. A continuación, se señalan las posibilidades de actuación municipal más destacables.

\subsection{La fijación de valores de iluminación más estrictos que los establecidos con carácter general por la normativa autonómica}

Los municipios están facultados para fijar valores de iluminación más estrictos que los establecidos con carácter general por la normativa autonómica. Lo que no podrían, en ningún caso, es rebajar el nivel de protección establecido por la comunidad autónoma correspondiente, que tendrá el carácter

\footnotetext{
111 Así se prevé también en la Propuesta de Modelo de Ordenanza municipal de alumbrado exterior..., cit., cuyo artículo 22.3 establece que «Los instrumentos de planeamiento y proyectos de obras en los que se incluyan determinaciones relativas a la red de alumbrado público, se redactarán de tal modo que se garantice el cumplimiento de las obligaciones establecidas en esta Ordenanza».
} 
de mínimo. Así lo prevé de forma expresa la Ley de Cantabria 6/2006, de 9 de junio, cuyo artículo 8.3 dispone que

«Los Ayuntamientos podrán elevar el nivel de protección previsto en este artículo mediante las oportunas previsiones incorporadas a sus reglamentos y ordenanzas, así como a las determinaciones y normas de su planeamiento urbanístico. Las referidas prescripciones municipales no podrán en ningún caso reducir los niveles de protección determinados por la Comunidad Autónoma, que tendrán siempre el carácter de mínimos».

En Cataluña, la Ley 6/2001 prevé que los ayuntamientos pueden establecer valores propios de flujo de hemisferio superior instalado ${ }^{112}$ atendiendo a las características y especificidades de su territorio, siempre que no disminuya la protección otorgada en virtud de los niveles máximos de luz establecidos reglamentariamente para cada uno de los usos especificados por el artículo 4.2, salvo que concurran causas justificadas, de acuerdo con lo que sea regulado por vía reglamentaria (art. 6.4). Igualmente, el Decreto 82/2005 prevé que «Los ayuntamientos pueden establecer valores propios de flujo luminoso al hemisferio superior instalado, considerando a las características y especificidades de su término municipal, siempre y cuando eso no suponga una disminución del nivel de protección otorgada por este reglamento, especialmente en las áreas descritas en el artículo 5.3 $3^{113}$ 》 (art. 9.1).

\subsection{La regulación del régimen horario del alumbrado}

Los ayuntamientos ostentan un amplio margen de maniobra en la regulación horaria de la iluminación exterior que se materializa en diferentes posibilidades de actuación:

— La fijación del régimen horario del alumbrado. La Ley cántabra 6/2006 atribuye a los Ayuntamientos la competencia para la determinación de las franjas horarias en que los alumbrados externos permanecerán apagados atendiendo a criterios de seguridad, vialidad, usos comerciales, industriales o deportivos y a las necesidades de iluminación nocturna de monumentos y otros elementos de interés cultural, histórico o turístico (art. 10.1 y 2). No obstante, se prevé que el Gobierno de Cantabria, reglamentariamente, fijará un régimen horario de uso del alum-

\footnotetext{
${ }^{112}$ El «flujo de hemisferio superior instalado» se define por esta Ley como el «flujo radiado por encima del plano horizontal por un aparato de iluminación o por un cuerpo, un edificio o un elemento luminoso» [art. 4.1.j)].

${ }^{113}$ El artículo 5.3 del Decreto 82/2005 establece que «La iluminación en suelo urbano próximo a zonas de máxima protección (E1) o zonas acuáticas marinas y continentales, será especialmente respetuosa en evitar efectos perturbadores en el medio. Si procede, el Departamento de Medio Ambiente y Vivienda de acuerdo con el ayuntamiento puede determinar características de iluminación correspondientes a zona E2 (FHS y tipo de lámpara) para garantizar una mayor protección en función de las particularidades de la zona a proteger».
} 
EL PAPEL DE LOS MUNICIPIOS EN LA PREVENCIÓN, ORDENACIÓN Y CONTROL...

brado exterior que será de aplicación en aquellos municipios que no hayan establecido su propio horario.

- La posibilidad de establecer en su término municipal horarios de noche más amplios. En Cataluña, el Decreto 82/2005, de 3 de mayo, establece con carácter general el horario de noche $\mathrm{u}$ horario nocturno a partir de las 22 horas UTC (Tiempo Universal Coordinado) hasta la salida del sol, y el horario de atardecer para aquellas horas que van desde que se pone el sol hasta las 22 horas UTC. Sin embargo, los ayuntamientos pueden establecer en su término municipal horarios de noche más amplios (art. 10.2), para reforzar la protección frente a la contaminación lumínica.

- La regulación de un régimen propio de alumbrado para los acontecimientos nocturnos singulares, festivos, feriales, deportivos o culturales al aire libre, que han de compatibilizar la prevención de la contaminación lumínica y el ahorro energético con las necesidades derivadas de estos acontecimientos. Así lo prevén las Leyes de Cataluña, Islas Baleares y Comunidad Foral de Navarra (arts. 8.2, 9.2 y 10.2, respectivamente). En el caso de Cantabria, los ayuntamientos deben solicitar a la Consejería competente en materia de medio ambiente autorización para establecer previsiones diferenciadas y un horario propio de alumbrado en atención a circunstancias especiales como la celebración al aire libre de acontecimientos nocturnos singulares de índole festiva, deportiva o cultural (art. 10.3).

— El otorgamiento de la autorización correspondiente para la iluminación ornamental en períodos de funcionamiento superiores a una semana, previa presentación de la memoria justificativa. Así lo establece el artículo 10.4 del Decreto catalán 82/2005, de 3 de mayo ${ }^{114}$.

\subsection{El control de la iluminación en horario nocturno}

A los ayuntamientos también les corresponde el control de la iluminación en horario de noche. Este control se manifiesta a través de diferentes intervenciones municipales, entre las que destacan las siguientes:

- Los proyectos de instalación de alumbrados que deban funcionar en horario nocturno irán acompañados de una memoria que justifique su necesidad $^{115}$. En Cataluña, para la iluminación en horario de noche en

\footnotetext{
${ }^{114}$ Este Decreto también prevé que los ayuntamientos pueden establecer períodos especiales de iluminación ornamental en el período navideño (como máximo, entre el penúltimo viernes del mes de noviembre y el 6 de enero; durante este período se autorizará un máximo de 168 horas de funcionamiento de iluminación ornamental), las festividades locales de acuerdo con el calendario anual establecido por cada ayuntamiento y en temporada de alta afluencia turística de acuerdo con la normativa sectorial (art. 10.3).

115 Artículos 6.3 de la Ley catalana 6/2001, de 31 de mayo; 6.3 de la Ley balear 3/2005, de 20 de abril; y 7.3 de la Ley Foral 10/2005, de 9 de noviembre.
} 
las zonas E3 y E4 debe presentarse esta memoria justificativa al ayuntamiento y será necesaria su autorización expresa, previo informe de la Oficina para la Prevención de la Contaminación Luminosa (art. 9.9 del Decreto 82/2005).

- Los ayuntamientos, en Cataluña, deben emitir resolución en aquellos casos excepcionales en que la iluminación reglamentada para áreas destinadas a actividades industriales, comerciales, de servicios, deportivas, recreativas y equipamientos al exterior provocase una iluminación intrusa superior a la fijada, una vez que el responsable de la actividad presente al ayuntamiento una justificación razonada (art. 9.11, primer párrafo, del Decreto 82/2005).

- En Cataluña, el funcionamiento en horario de noche queda sujeto a la autorización del ayuntamiento, previo informe de la Oficina para la Prevención de la Contaminación Luminosa ${ }^{116}$. En las zonas E1 esta autorización sólo podrá emitirse limitada a fechas concretas (art. 9.11, párrafo tercero, del Decreto 82/2005).

\subsection{La obligación de adecuación de los alumbrados públicos municipales a las prescripciones normativas}

Una de las principales consecuencias que se derivan de la entrada en vigor de las normas autonómicas sobre contaminación lumínicas aprobadas hasta la fecha es la obligación de adaptación de los alumbrados exteriores existentes a las prescripciones normativas, obligación que afecta también a los municipios en tanto que administraciones competentes y titulares del servicio de alumbrado público. De este modo, las leyes autonómicas determinan que los alumbrados exteriores existentes a su entrada en vigor (debe entenderse públicos y privados) deben adaptarse a sus previsiones y a las de la normativa que las desarrolle en los plazos que se fijen por vía reglamentaria, que en ningún caso podrán exceder de ocho años ${ }^{117}$, y que se determinarán atendiendo, entre otros, a los siguientes criterios ${ }^{118}$ : los usos del alumbrado, la clasifica-

\footnotetext{
${ }_{116}$ Debe tenerse en cuenta que, de acuerdo con el artículo 10.5 del Decreto 82/2005, con carácter general, en horario nocturno sólo se permite el funcionamiento de rótulos luminosos que cumplan una función informativa necesaria de localización de servicios (farmacias, transportes públicos, hoteles, gasolineras...), y únicamente mientras se dé el servicio. No se admiten, en horario de noche, rótulos de carácter comercial y/o publicitario.

${ }^{117}$ En Cataluña, el Decreto 82/2005, de 3 de mayo, ha fijado como fecha máxima para la adaptación de la iluminación exterior existente a su entrada en vigor, tanto de titularidad pública como privada, el 31 de agosto de 2009 (disposición transitoria $3^{\mathrm{a}}$ ).

${ }_{118}$ En cambio, si posteriormente a la entrada en vigor de la correspondiente Ley autonómica se llevase a cabo una modificación sustancial de un alumbrado exterior que afecta a su intensidad, espectro o flujo de hemisferio superior instalado, se ajustará, en todo caso, a las prescripciones de esta Ley y de la normativa que la desarrolle (véase la disposición adicional $2^{\text {a }}$ de las Leyes de Cataluña 6/2001, de 31 de mayo; Islas Baleares 3/2005, de 20 de abril; Comunidad Foral de Navarra 10/2005, de 9 de noviembre; y Cantabria 6/2006, de 9 de junio).
} 
EL PAPEL DE LOS MUNICIPIOS EN LA PREVENCIÓN, ORDENACIÓN Y CONTROL...

ción de la zona en la que se emplaza el alumbrado, los perjuicios que causa el alumbrado para el medio o para la ciudadanía, la magnitud de las reformas que se deban llevar a cabo, la eficiencia energética del alumbrado, los costes económicos de la adaptación y la población o el carácter singular de cada municipio ${ }^{119}$.

En Cataluña, para garantizar el cumplimiento de esta obligación de adecuación de los alumbrados exteriores existentes a la nueva normativa, el Decreto 82/2005 obliga a los ayuntamientos a formular un plan municipal de adecuación de la iluminación exterior existente de su municipio a las prescripciones de la Ley 6/2001 y del Decreto 82/2005 (art. 12), que se deberá comunicar a la Oficina para la Prevención de la Contaminación Luminosa antes del 31 de diciembre de 2007 (disposición transitoria $2^{\mathbf{a}}$, apartado primero). Este plan debe concretar el programa de actuaciones para la adaptación del alumbrado público y las acciones para promover la adecuación de la iluminación exterior de titularidad privada. El Plan debe contener el análisis de la iluminación exterior por zonas de protección a la contaminación luminosa del municipio, las actuaciones priorizadas y el calendario de ejecución de la adaptación, en función de la incidencia de la contaminación luminosa en el medio ambiente (art. 12.1 del Decreto 82/2005). Se trata, pues, de una obligación a la cual todos los ayuntamientos catalanes deberán dar cumplimiento en los próximos años.

Sin embargo, no se puede obviar el coste que para muchos municipios supondrá tanto la elaboración de este Plan como el propio cumplimiento de la obligación de adaptación de la iluminación exterior pública ${ }^{120}$, así como las insuficiencias de carácter técnico, económico y personal de muchos de ellos. Por este motivo, el Decreto 82/2005 dispone que la Oficina para la Protección de la Contaminación Luminosa asesorará y colaborará con los ayuntamientos para la redacción de estos planes (art. 12.2). Asimismo, prevé que el Departamento de Medio Ambiente y Vivienda realizará el asesoramiento para elaborar y promover planes piloto en el ámbito comarcal de proyectos de adecuación de los alumbrados existentes a los requerimientos normativos; y convocará ayudas para la ejecución de los planes municipales de adaptación de la iluminación exterior a partir de los presupuestos de

\footnotetext{
119 Véase la disposición transitoria $1^{\text {a }}$ de las Leyes de Cataluña 6/2001, de 31 de mayo; Islas Baleares 3/2005, de 20 de abril; Comunidad Foral de Navarra 10/2005, de 9 de noviembre; y Cantabria 6/2006, de 9 de junio. Téngase en cuenta que, aunque los alumbrados exteriores existentes a la entrada en vigor de estas Leyes pueden mantener inalteradas sus condiciones técnicas, en los términos que establece la disposición transitoria $1^{\text {a }}$, habrán de ajustar el régimen de u sos horarios a lo que determinan estas normas (véase la disposición adicional $1^{a}$ de las Leyes de Cataluña 6/2001, de 31 de mayo; Islas Baleares 3/2005, de 20 de abril; Comunidad Foral de Navarra 10/2005, de 9 de noviembre; y Cantabria $6 / 2006$, de 9 de junio).

${ }_{120}$ El Departamento de Medio Ambiente y Vivienda de la Generalidad de Cataluña ha calculado que la inversión asociada a la adecuación de las actuales instalaciones de iluminación exterior de Cataluña se valora en unos 40 millones de euros. Sin embargo, esta inversión queda compensada por el ahorro energético anual que produce esta adecuación, de tal manera que el coste de la inversión se podría amortizar en menos de 4 años.
} 
2006 ${ }^{121}$. Mediante la Orden MAH/159/2006, de 29 de marzo, el Departamento de Medio Ambiente y Vivienda ha aprobado las bases reguladoras de las ayudas para actuaciones de ordenación ambiental de la iluminación exterior y ha abierto la convocatoria para el año $2006^{122}$. Son objeto del otorgamiento de estas ayudas los proyectos y las actuaciones de adecuación de la iluminación exterior existente antes del 4 de mayo de 2005 que se puedan considerar en alguno de los apartados siguientes ${ }^{123}$ :

a) Redacción de los Planes municipales para la adecuación de la iluminación exterior existente. Son objeto de subvención las propuestas que alcancen todos los planes de una comarca. Pueden acogerse a estas ayudas los consejos comarcales que tengan la voluntad de redactar los planes municipales de adecuación de la iluminación exterior de su comarca y los ayuntamientos que quieran ejecutar proyectos de adecuación de la iluminación exterior existente.

b) Actuaciones o ejecución de proyectos de adecuación de la iluminación exterior existente. Puede ser objeto de subvención la adquisición de material consistente en lámparas, pantallas, reguladores horarios y reductores de flujo luminoso. Pueden acogerse a estas ayudas los ayuntamientos que quieran ejecutar proyectos de adecuación de la iluminación exterior existente.

Recientemente, mediante la Resolución MAH/377/2007, de 8 de febrero, se ha hecho pública la convocatoria de ayudas para la realización de actuaciones de ordenación ambiental de la iluminación exterior correspondientes al año 2007, que se regirá por las bases reguladoras aprobadas mediante la Orden MAH/159/2006, de 29 de marzo ${ }^{124}$.

A partir de la entrada en vigor del Decreto 82/2005, las modificaciones de las instalaciones de la iluminación exterior existentes deben cumplir los requerimientos de este reglamento (disposición adicional $\left.1^{\mathrm{a}}\right)^{125}$.

\footnotetext{
121 También prevén la colaboración de la Administración autonómica con los ayuntamientos para garantizar la adaptación de los alumbrados públicos municipales las Leyes de Baleares 3/2005, de 20 de abril (disposición transitoria $2^{\mathbf{a}}$ ), de Navarra 10/2005, de 9 de noviembre (disposición transitoria $2^{\mathbf{a}}$ ) y de Cantabria 6/2006, de 9 de junio (disposición transitoria $2^{\mathbf{a}}$ ).

${ }_{122}$ Posteriormente, mediante las Órdenes MAH/293/2006, de 9 de junio y MAH 357/2006, de 5 de julio, se ha modificado la dotación presupuestaria de la convocatoria de ayudas para actuaciones de ordenación ambiental de la iluminación exterior, aprobada por la Orden MAH/159/2006, de 29 de marzo.

123 Para redactar los planes locales y ejecutar los proyectos de adecuación de la iluminación exterior, el Departamento de Medio Ambiente y Vivienda destinó inicialmente 900.000 euros, cantidad que fue ampliada posteriormente hasta 2.366.243,80 euros.

${ }^{124}$ La dotación máxima que se destinará a estas ayudas durante el año 2007 es de 1.076 .000 euros.

125 Téngase en cuenta que la disposición adicional $2^{\text {a }}$ de la Ley catalana 6/2001 preveía que si, con posterioridad a la entrada en vigor de esta Ley se llevaba a cabo una modificación sustancial de un alumbrado exterior que afectase a la intensidad, el espectro o el flujo de hemisferio superior instalado, debía ajustarse, en todo caso, a las prescripciones de la Ley y de la normativa que la desarrolle.
} 


\section{La incorporación del control lumínico en determinados mecanismos de intervención administrativa}

Los municipios, en tanto que administraciones públicas con importantes competencias sobre el alumbrado, la protección del medio ambiente, el urbanismo..., estás llamados a intervenir de forma decisiva para asegurar el cumplimiento de los objetivos perseguidos por la legislación autonómica aprobada en materia de contaminación lumínica. Sin perjuicio de otras actuaciones, una intervención fundamental de los municipios en este ámbito es la de incorporación del control lumínico en determinadas intervenciones locales, como la concesión de licencias, la contratación administrativa o las obras sufragadas con fondos públicos.

En primer lugar, los ayuntamientos deben velar por que las características de los alumbrados exteriores (también alumbrados interiores, si producen intrusión lumínica en el exterior), ajustadas a las disposiciones de la normativa autonómica aprobada a tal efecto, se hagan constar en los proyectos técnicos anexos a las solicitudes de aprobación de proyectos e instrumentos urbanísticos y proyectos de urbanización y licencias de obras ${ }^{126}$. En Cataluña, el Decreto 82/2005, de 3 de mayo, de desarrollo de la Ley 6/2001, ha concretado que los proyectos de iluminación exterior promovidos por particulares o entes públicos que requieran la licencia de obras u otras licencias de intervención municipal deben acreditar el cumplimiento de los requerimientos establecidos por este Decreto mediante un informe firmado por el autor del proyecto ${ }^{127}$. En Cantabria, en cambio, «los promotores de obras e instalaciones podrán aportar como prueba suficiente el certificado del órgano autonómico competente de que las luminarias que se pretenden utilizar cumplen las prescripciones técnicas pertinentes» (art. 13.3 de la Ley 6/2006).

En segundo lugar, los municipios también deben verificar que las características de los alumbrados exteriores (y alumbrados interiores, si producen intrusión lumínica en el exterior) se hagan constar en los proyectos técnicos anexos a las solicitudes de la correspondiente licencia ambiental (por ejemplo, autorización ambiental, licencia ambiental o comunicación o licencia de apertura, en Cataluña, de acuerdo con la Ley 3/1998, de 27 de febrero, de la

\footnotetext{
126 Véanse los artículos 11.1 de la Ley balear 3/2005 y 12.1 de la Ley navarra 10/2005 (este precepto exige, además, un informe preceptivo previo al acuerdo municipal por parte del Departamento competente del Gobierno de Navarra). Por su parte, el artículo 13.2 de la Ley de Cantabria 6/2006 dispone que «Las entidades locales no otorgarán licencias de obras o apertura de establecimientos en las que no se garantice, en el correspondiente proyecto, el cumplimiento de las prescripciones técnicas a que se refiere esta Ley».

127 Artículo 16.1 del Decreto 82/2005. Este informe de las características de la iluminación exterior debe incluir los aspectos siguientes: descripción del proyecto, zona de protección frente a la contaminación luminosa donde se ubica la instalación, características de las instalaciones y de los aparatos de iluminación, sistemas de regulación horaria, programa de mantenimiento de las instalaciones y de los aparatos de iluminación y memoria justificativa de uso en horario nocturno, si procede (art. 16.2 del Decreto 82/2005).
} 
intervención integral de la administración ambiental; o autorización ambiental integrada o licencia municipal de apertura, en el caso de Navarra ${ }^{128}$ ).

En tercer lugar, los municipios (y todas las administraciones públicas en el ámbito de la comunidad autónoma correspondiente) también están obligados, en esta materia, a incluir en los pliegos de cláusulas administrativas de los contratos administrativos en los que proceda los requisitos que ha de cumplir necesariamente el alumbrado exterior para ajustarse a a los criterios de prevención y corrección de la contaminación lumínica establecidos por la normativa autonómica' ${ }^{129}$.

Finalmente, los municipios también deberán garantizar que los proyectos de alumbrado exterior en construcciones, instalaciones y viviendas financiados con fondos públicos se ajustan necesariamente a los criterios de prevención de la contaminación lumínica y eficiencia energética fijados por la legislación vigente. Así lo prevén las leyes de Cataluña (art. 12), Islas Baleares (art. 13) y Comunidad Foral de Navarra (art. 14).

\section{La intervención municipal de control, inspección y sanción}

Correlato necesario de la actuación municipal canalizada a través de todo el conjunto de medidas preventivas que se ha analizado es la previsión de amplias competencias municipales en materia de control, inspección y sanción.

En primer lugar, los ayuntamientos están facultados para realizar actividades de control e inspección en materia de contaminación lumínica, a fin de garantizar el cumplimiento de las prescripciones normativas. De este modo, la Ley catalana 6/2001 atribuye al Departamento de Medio Ambiente y Vivienda y a los ayuntamientos «la potestad de inspección y control de los alumbrados que puedan ser fuente de contaminación lumínica», que es ejercida por personal acreditado al servido de la Administración respectiva, que tiene la condición de autoridad, sin perjuicio de la posible intervención de entidades colaboradoras (art. 24.1). También la ley cántabra 6/2006 faculta a la Administración de la comunidad autónoma y a los ayuntamientos para realizar las actuaciones de vigilancia e inspección que tengan por conveniente para garantizar el cumplimiento de las prescripciones legales (art. 23.1) ${ }^{130}$. Por

\footnotetext{
${ }^{128}$ Artículos 10.1 de la Ley catalana 6/2001 y 13.1 de la Ley cántabra 6/2006.

129 Artículos 11.1 de la Ley de Cataluña 6/2001 (véase también el art. 16.3 del Decreto 82/2005), 12.1 de la Ley de Baleares 3/2005, 13.1 de la Ley de Navarra 10/2005 y 13.4 de la Ley de Cantabria 6/2006.

${ }^{130}$ Estas actividades se llevarán a cabo por los funcionarios designados a tal efecto y acreditados por el órgano del que dependan (aunque también se prevé que pueden llevarse a cabo por entidades colaboradoras, debidamente autorizadas por la comunidad autónoma, sin que por ello el personal al servicio de las mismas adquiera la condición de agente de la autoridad). Este personal, para el ejercicio de sus funciones, gozará de la consideración de agente de la autoridad y podrá ser auxiliado y acompañado por asesores u otro personal técnico debidamente identificado. La comunidad autónoma establecerá los mecanismos de coordinación de las actividades inspectoras que se desarrollen en esta materia. Véase el artículo 23, apartados 3, 4, 5 y 6 de la Ley de Cantabria 6/2006.
} 
EL PAPEL DE LOS MUNICIPIOS EN LA PREVENCIÓN, ORDENACIÓN Y CONTROL...

su parte, la ley balear 3/2005 atribuye estas mismas competencias «al departamento de Medio Ambiente de los consejos insulares y a los ayuntamientos» $(\text { art. 26.1) })^{131}$.

Asimismo, los entes locales disponen de competencias sancionadoras en esta materia. La Ley catalana 6/2001, de 31 de mayo, atribuye la potestad sancionadora a la Administración de la Generalidad y a los entes locales (art. $23.1)^{132}$; la Ley balear 3/2005, de 20 de abril, a la administración del consejo insular y a los entes locales (art. 25.1); y la Ley cántabra 6/2006, de 9 de junio, a la administración autonómica y a los municipios. Concretamente, en el ámbito de la comunidad autónoma serán competentes para imponer sanciones el Consejo de Gobierno y el Consejero competente en materia de medio ambiente (art. 20.2); asimismo, corresponde, en exclusiva, al Consejo de Gobierno de la Comunidad Autónoma de Cantabria, la competencia para imponer sanciones por infracciones muy graves (art. 20.3). En cambio, la competencia para imponer sanciones por infracciones graves y leves será indistinta de los Ayuntamientos y del Consejero responsable del medio ambiente de la Administración autonómica. A efectos de coordinar dicha competencia, «cuando una de las dos Administraciones inicie un expediente sancionador lo comunicará de inmediato a la otra a efectos de que esta última no adopte medida alguna que menoscabe el expediente sancionador iniciado, que continuará y tramitará en los términos, marco o condiciones a que se refiere el apartado 1 de este artículo [la Ley 30/1992, de 26 de noviembre, de régimen jurídico de las administraciones públicas y del procedimiento administrativo común]» (art. 20.4). Asimismo, esta Ley permite que la Administración autonómica delegue en los municipios el ejercicio de la competencia sancionadora que a ella le corresponda, excepto la competencia para imponer sanciones por infracciones muy graves (art. 20.5) ${ }^{133}$.

\footnotetext{
${ }^{131}$ La Ley Foral 10/2005 no concreta las competencias municipales en esta materia, sino que remite al desarrollo reglamentario de la Ley para su establecimiento. El artículo 19.1 establece que «La competencia de inspección y denuncia de las infracciones que se produzcan a los preceptos y obligaciones establecidos en la presente Ley Foral se atribuye a aquellas Administraciones a las que, reglamentariamente, se les asigne el cumplimiento y la exigencia de cumplimiento de lo preceptuado en esta Ley Foral».

${ }^{132}$ El Decreto 82/2005, de 3 de mayo, ha concretado que corresponde a los órganos competentes de las entidades locales la incoación y tramitación de los expedientes sancionadores instruidos por infracciones tipificadas como leves y graves (art. 22.1). En cambio, corresponde a los Servicios Territoriales del Departamento de Medio Ambiente y Vivienda la incoación y tramitación de los expedientes sancionadores instruidos por infracciones tipificadas como muy graves (art. 22.2). Y, por lo que hace referencia a los órganos competentes para la resolución de los expedientes sancionadores, el alcalde/esa es el órgano competente para la resolución de los expedientes sancionadores incoados por infracciones tipificadas como leves y graves; y el/la directora/a general de Calidad Ambiental, para la resolución de los expedientes sancionadores incoados por infracciones tipificadas como muy graves (art. 25.1 y 2). En cualquier caso, los órganos competentes para sancionar, de conformidad con lo que establecen los párrafos anteriores, se comunicarán mutuamente las sanciones firmes que hayan impuesto (art. 25.3).

${ }^{133}$ La Ley Foral 10/2005, de 9 de noviembre, remite al desarrollo reglamentario la concreción de las competencias de inspección y sanción. Únicamente prevé, de forma muy genérica, que será la Administración que ha realizado la inspección y denuncia la que tiene atribuida la competencia para iniciar el procedimiento sancionador que reglamentariamente se establezca; y que será el Departamento de
} 
Como aspecto más destacable, la Ley de Cantabria, además de reconocer la competencia sancionadora de los municipios, también da entrada a la competencia municipal para tipificar infracciones y sanciones en materia de contaminación lumínica distintas de las contenidas en esta Ley. El artículo 19 prevé que las ordenanzas municipales, de conformidad con lo previsto en la legislación de régimen local, podrán tipificar infracciones y sanciones distintas de las contenidas en esta Ley conforme a los siguientes criterios:

«a) Las infracciones podrán ser graves o leves y se tipificarán en atención al incumplimiento de los deberes establecidos en esta Ley y en sus normas de desarrollo en relación con las actividades a que ella se refiere en el término municipal de que se trate, considerando el grado de perturbación, menoscabo o impedimento que dicho incumplimiento suponga para la integridad del medio ambiente lumínico así como para el cumplimiento de los objetivos y principios de la presente Ley.

b) Las sanciones consistirán en multas y no podrán alcanzar una cuantía superior a la prevista para las infracciones graves en la Ley 7/1985, de 2 de abril, Reguladora de las Bases de Régimen Local» ${ }^{134}$.

\section{BIBLIOGRAFÍA ESPECÍFICA SOBRE CONTAMINACIÓN LUMÍNICA}

Betancor RodrígueZ, A., Instituciones de Derecho Ambiental, La Ley, Madrid, 2001; CAlvo Charro, M., «El derecho a ver las estrellas. Análisis de la contaminación lumínica desde una perspectiva jurídica», en Revista de Derecho Urbanístico y Medio Ambiente, núm. 187, 2001; CAlvo ChARRO, M., «La contaminación lumínica. La protección del cielo oscuro», en su libro Escritos de Derecho Ambiental, Tirant lo Blanch, Valencia, 2003, pp. 2378; Calvo Charro, M., voz «Contaminación lumínica», en la obra colectiva dirigida por Enrique Alonso GARCía y Blanca LOZANO CuTANDA, Diccionario de Derecho Ambiental, Iustel, Madrid, 2006, pp. 382-393; CASADO CASADO, L., «Las administraciones públicas ante la contaminación lumínica. Análisis del modelo de prevención y control instaurado en Cataluña», en Revista Española de Derecho Administrativo, núm. 134, 2007; ENTRENA RUIZ, D., «La prevención contra la contaminación lumínica mediante la ordenación del territorio y urbanismo», en Ecosostenible, julio de 2005 , pp. 20-26; Esteve PARDO, J., Técnica, riesgo y Derecho. Tratamiento del riesgo tecnológico en el Derecho ambiental, Ariel, Barcelona, 1999; FORTES MARTÍN, A., «La creciente preocupación normativa por la protección ambiental del medio nocturno», en Ecosostenible, junio de 2005; pp. 20-24; GALADÍ-

\footnotetext{
Medio Ambiente, Ordenación del Territorio y Vivienda el órgano competente para el inicio y tramitación del procedimiento sancionador de las infracciones tipificadas como muy graves (véase el artículo 19).

${ }^{134}$ De acuerdo con el artículo 141 de la LBRL, las multas por infracción de ordenanzas locales, salvo previsión legal distinta, deberán respetar las siguientes cuantías: infracciones muy graves: hasta 3.000 euros; infracciones graves: hasta 1.500 euros; e infracciones leves: hasta 750 euros.
} 
EL PAPEL DE LOS MUNICIPIOS EN LA PREVENCIÓN, ORDENACIÓN Y CONTROL...

ENRÍQUEZ, D., «La ordenanza sobre protección del cielo nocturno en Córdoba: un caso de interés general que debe hacernos reflexionar», en Tribuna de Astronomía y Universo, núm. 5, noviembre de 1999; IDAE, Propuesta de Modelo de Ordenanza Municipal de alumbrado exterior para la protección del medio ambiente mediante la mejora de la eficiencia energética, Instituto para la Diversificación y Ahorro de la Energía (IDAE), Madrid, 2002; IOARRAGUIRRE, J., «La contaminació lumínica i la resposta social», en $S A M$, Suport a la gestió ambiental d'activitats en el municipi, núm. 8, Diputación de Barcelona, junio de 2003; JAUME FERNÁNDEZ, C., «La contaminación lumínica en nuestros municipios. Reflexiones en torno a los instrumentos jurídicos para combatirla desde los Ayuntamientos», en Ayuntamiento XXI, núm. 4, 2002; PUJOL, F., «¿Qué fue del cielo estrellado?. Algunas propuestas para reducir la contaminación lumínica», en Ambienta, núm. 42, marzo de 2005, pp. 29-33; RODRÍGUEZ FonT, M., «La Llei catalana d'ordenació ambiental de l'enllumenat per a la protecció del medi nocturn», en Autonomies. Revista Catalana de Dret Públic, núm. 28, 2002, pp. 83-96; RodRíGUEz FonT, M., «La contaminació lumínica», en la obra colectiva coordinada por José EsTEVE PARDO, Derecho del Medio Ambiente y Administración Local, $2^{\mathrm{a}}$ edición ( $1^{\mathrm{a}}$ en la Fundación), Fundación Democracia y Gobierno Local, Barcelona, 2006, pp. 643-651; Sociedad de Ciencias ARANZadi (Departamento de AstroNOMía) y CADEM-Grupo Eve (UnIDAD DE TERCIARIO), Consideraciones sobre el uso racional de la energía y la contaminación lumínica en las instalaciones de alumbrado exterior, Diputación Foral de Guipúzcoa, 2006. 


\section{Jurisprudencia}

REALA-2007, núm. 304. LUCÍA CASADO CASADO. EL PAPEL DE LOS MUNICIPIOS EN LA PREVENCIÓN, ORDENACIÓN Y... 